\title{
CENP-A nucleosomes localize to transcription factor hotspots and subtelomeric sites in human cancer cells
}

\author{
Rajbir K Athwal ${ }^{1,2 \dagger}$, Marcin P Walkiewicz ${ }^{1,2 \dagger}$, Songjoon Baek², Song Fu ${ }^{1,2}$, Minh Bui1 ${ }^{1,2}$, Jordi Camps ${ }^{3}$, Thomas Ried ${ }^{3}$, \\ Myong-Hee Sung ${ }^{2}$ and Yamini Dalal ${ }^{*}$
}

\begin{abstract}
Background: The histone $\mathrm{H} 3$ variant CENP-A is normally tightly regulated to ensure only one centromere exists per chromosome. Native CENP-A is often found overexpressed in human cancer cells and a range of human tumors. Consequently, CENP-A misregulation is thought to contribute to genome instability in human cancers. However, the consequences of such overexpression have not been directly elucidated in human cancer cells.

Results: To investigate native CENP-A overexpression, we sought to uncover CENP-A-associated defects in human cells. We confirm that CENP-A is innately overexpressed in several colorectal cancer cell lines. In such cells, we report that a subset of structurally distinct CENP-A-containing nucleosomes associate with canonical histone $\mathrm{H} 3$, and with the transcription-coupled chaperones ATRX and DAXX. Furthermore, such hybrid CENP-A nucleosomes localize to DNase I hypersensitive and transcription factor binding sites, including at promoters of genes across the human genome. A distinct class of CENP-A hotspots also accumulates at subtelomeric chromosomal locations, including at the $8 \mathrm{q} 24 / \mathrm{Myc}$ region long-associated with genomic instability. We show this 8q24 accumulation of CENP-A can also be seen in early stage primary colorectal tumors.

Conclusions: Our data demonstrate that excess CENP-A accumulates at noncentromeric locations in the human cancer genome. These findings suggest that ectopic CENP-A nucleosomes could alter the state of the chromatin fiber, potentially impacting gene regulation and chromosome fragility.
\end{abstract}

\section{Background}

Hallmarks of the cancer state include large-scale gene expression changes [1], chromosomal rearrangement, and aneuploidy [2-6]. While the mechanistic basis for these events remains under investigation, such events have been attributed to DNA methylation changes [1], telomere disruption [7], repair and DNA damage pathway protein defects [8], replication distress [9], and misregulation of the centromere-specific histone $\mathrm{H} 3$ variant, CENPA [10-13]. CENP-A's normal function is to serve as the sole structural marker for centromeric chromatin identity [14], by directly associating with a triad of inner kinetochore

\footnotetext{
*Correspondence: dalaly@mail.nih.gov

'Equal contributors

${ }^{1}$ Chromatin Structure and Epigenetics Mechanisms Unit, Center for Cancer Research, National Cancer Institute National Institutes of Health, 41 Center Drive, Bethesda, MD 20892, USA

Full list of author information is available at the end of the article
}

proteins CENP-C, CENP-N and CENP-B [15], which in turn recruit the rest of the kinetochore and microtubules to ensure faithful genome segregation during mitosis [16]. Consequently, mislocalization of CENP-A to noncentromere regions is believed to be a prognostic marker for aneuploidies driven by chromosomal breakage and rearrangements, emanating from bicentric chromosomes $[10,11,13,17,18]$. Indeed, artificial overexpression studies in flies demonstrate that under certain conditions, CENP-A can seed neocentromeres $[17,19]$. However, when moderately overexpressed to the levels similar to that previously seen in cancer cells $[10,11]$, CENP-A does not easily seed neocentromeres [20], but rather expands centromere domains [21]. In related studies, overexpressed yeast or Drosophila CENP-A accumulates in the euchromatic arms, where it is continually targeted for proteolysis and subsequently degraded $[22,23]$. Indeed, a recent study confirms this occurs also in human HeLa cells, wherein forced 
artificial overexpression of tagged CENP-A results in accumulation at ectopic locations [24]. However, although CENP-A mRNA is innately overexpressed several fold in a number of human solid tumors, including colorectal tumors [10,11,18,25-27], its behavior in cancer cells has not been investigated.

To elucidate consequences associated with CENP-A misregulation, we examined CENP-A mRNA and protein levels, partners, structure, and global nucleosome occupancy in human primary normal and colorectal cancers cells, as well as in primary tumors. We report that CENPA is overexpressed at the mRNA and protein level in some human colorectal cancers. This excess CENP-A partners with histone $\mathrm{H} 3$, and associates with transcriptionally coupled chaperones ATRX and DAXX in colorectal cancer cell lines. This distinct class of noncentromeric CENP-A nucleosomes forms a stable octameric nucleosomal species as detected by atomic force microscopy (AFM) and confirmed by high-resolution DNA analysis, which demonstrates binding of 150 to $170 \mathrm{bp}$ of DNA. These distinctive CENP-A nucleosomes localize to open regions of the genome as mapped by DNase I hypersensitivity (DHS), such as promoters of genes, and contain transcription factor binding motifs. In addition, we observe a correlation between large clusters of CENP-A and subtelomeric locations including the fragile region at $8 \mathrm{q} 24$. In this $8 \mathrm{q} 24$ region, we show that CENP-A is bound to CENP-C, a phenomena that also occurs in early human colorectal tumors, but not in normal human colon cells. Taken together, our data uncover a new role for a classical histone variant in human cancer cell lines.

\section{Results}

CENP-A is overexpressed, and ectopic CENP-A nucleosomes associate with H3, ATRX, and DAXX in colorectal cancer cells Early reports of innate overexpression of CENP-A in colorectal tumors date back well over a decade [10]. Thus, we focused on well-characterized colorectal cancer cell lines derived from different stages of tumor progression, such as SW480, HT29, DLD-1, and HCT116, comparing them to normal colon cells. We also included HeLa cells, since they have long been used as a model for human centromere biology [28,29]. We first examined total nuclear CENP-A protein across all the cell lines, using a sensitive fluorescence-based quantitative western blotting system (Figure 1A). Relative to normal colon cells, and standardized against internal amounts of the core histone H4, we observed CENP-A protein levels were slightly elevated in HeLa cells, lower in DLD-1, 1.35 fold overexpressed in HT29 and almost twofold overexpressed in the cell line SW480 (Figure 1A lower graph and Table 1 lists fold-values of all proteins tested in Figure 1A). To test whether the excess CENP-A protein in SW480 derived from excess mRNA, we next examined total CENP-A
mRNA levels. Indeed, semi-quantitative PCR analysis indicated that CENP-A mRNA is almost fourfold overexpressed in SW480 cells compared to normal colon cells (Figure 1B, lower panel depicts graphical representation of 4 replicates). We next examined levels of the CENP-A chaperone Holliday junction recognition protein (HJURP), which is required for accurate loading of CENP-A to centromeres [30-32]. Surprisingly, HJURP levels do not follow those of CENP-A; the cell line possessing the most CENP-A (SW480) has normal amounts of HJURP (Table 1). This finding intrigued us because, under normal conditions, HJURP restricts CENP-A loading to centromeric nucleosomes. We wondered whether histone $\mathrm{H} 3$ variant chaperones were also misregulated. We assessed transcription-coupled histone chaperones ATRX and DAXX, and observed that both are overexpressed in most cancer cell lines relative to normal colon, ranging from three- to twentyfold excess protein (Figure 1A, Table 1). Thus, these data demonstrate that CENP-A gene expression is innately misregulated in some colorectal cancer cells. To examine the consequences of variable amounts of this key histone variant, we chose to focus the rest of the study on three cell lines, spanning normal (normal colon), moderate (HeLa), and high (SW480) levels of CENP-A protein.

Histone variants such as H3.3/H2A.Z, which use chaperones like ATRX/DAXX, are generally excluded from centromeric CENP-A nucleosomes, and found either at pericentric regions [33] or at promoters of genes [34]. We wanted to assess potential co-occupancy of $\mathrm{H} 3$ / H2A.Z and CENP-A, when CENP-A and ATRX are misregulated, as well as potential sites in the genome where such co-associations might occur. To enrich for potential ectopic CENP-A nucleosomes, which might be at low abundance across the genome, we first devised a scheme to enrich noncentromeric CENP-A (Figure 1C shows a brief outline of the method). We used moderately micrococcal nuclease (MNase) digested nucleosomal arrays (Figure 1D) from normal colon, HeLa, and SW480 colorectal cells. From these inputs, we sought to enrich centromere-specific CENP-A nucleosomes (henceforth referred to as 'centromeric CENP-A') using native immunoprecipitation (IP) for the inner kinetochore protein CENP-B. CENP-B specifically binds a motif found in most centromeric alpha satellite DNA at every alternate CENP-A nucleosome in active centromeres [35]. Gentle sequential native CENP-A IP was applied to nucleosomes left unbound (UB) from this first step in order to enrich for centromere-depleted CENPA nucleosomes (henceforth referred to as 'ectopic CENP-A'). While this scheme does not allow for absolute elimination of centromeric CENP-A nucleosomes (due to the fact that CENP-A can localize to autosomal alpha satellite regions lacking CENP-B box), ectopic 
A

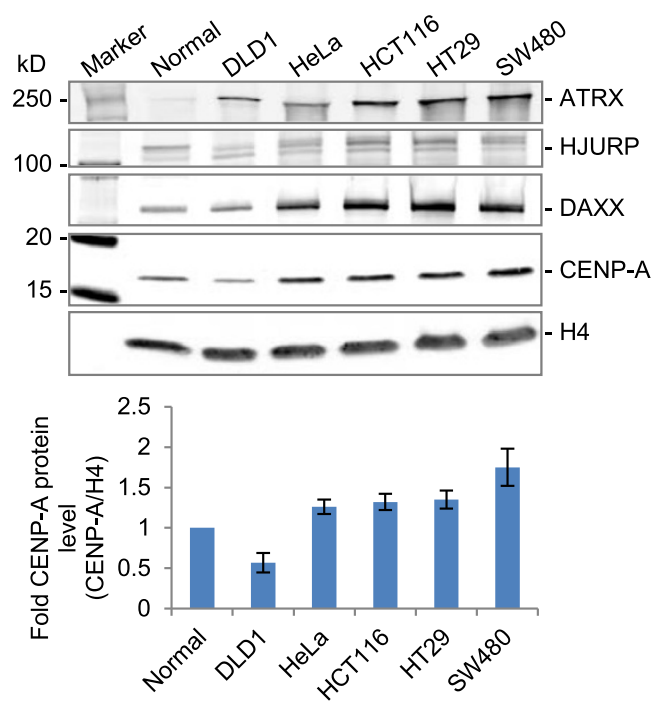

C

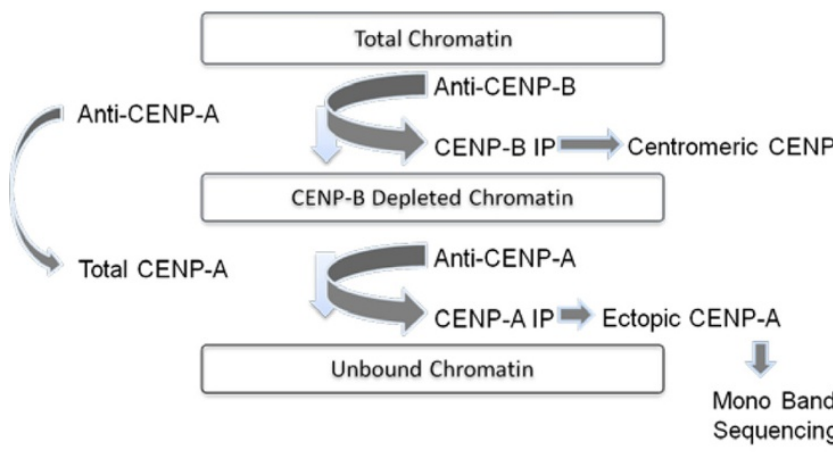

B
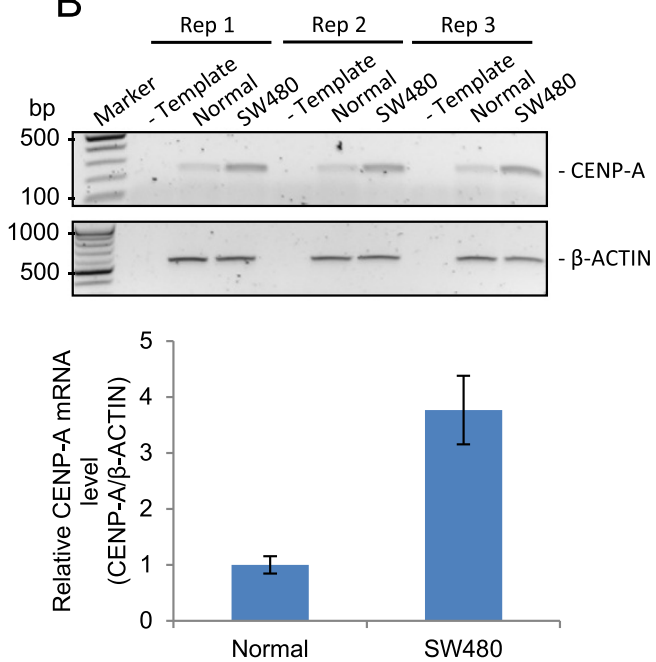

D

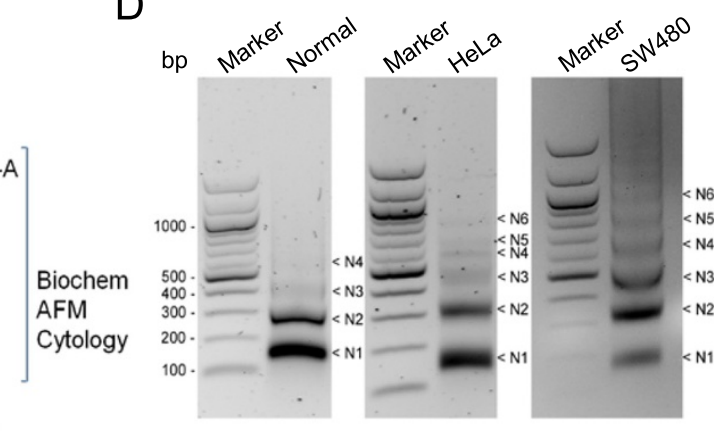

E
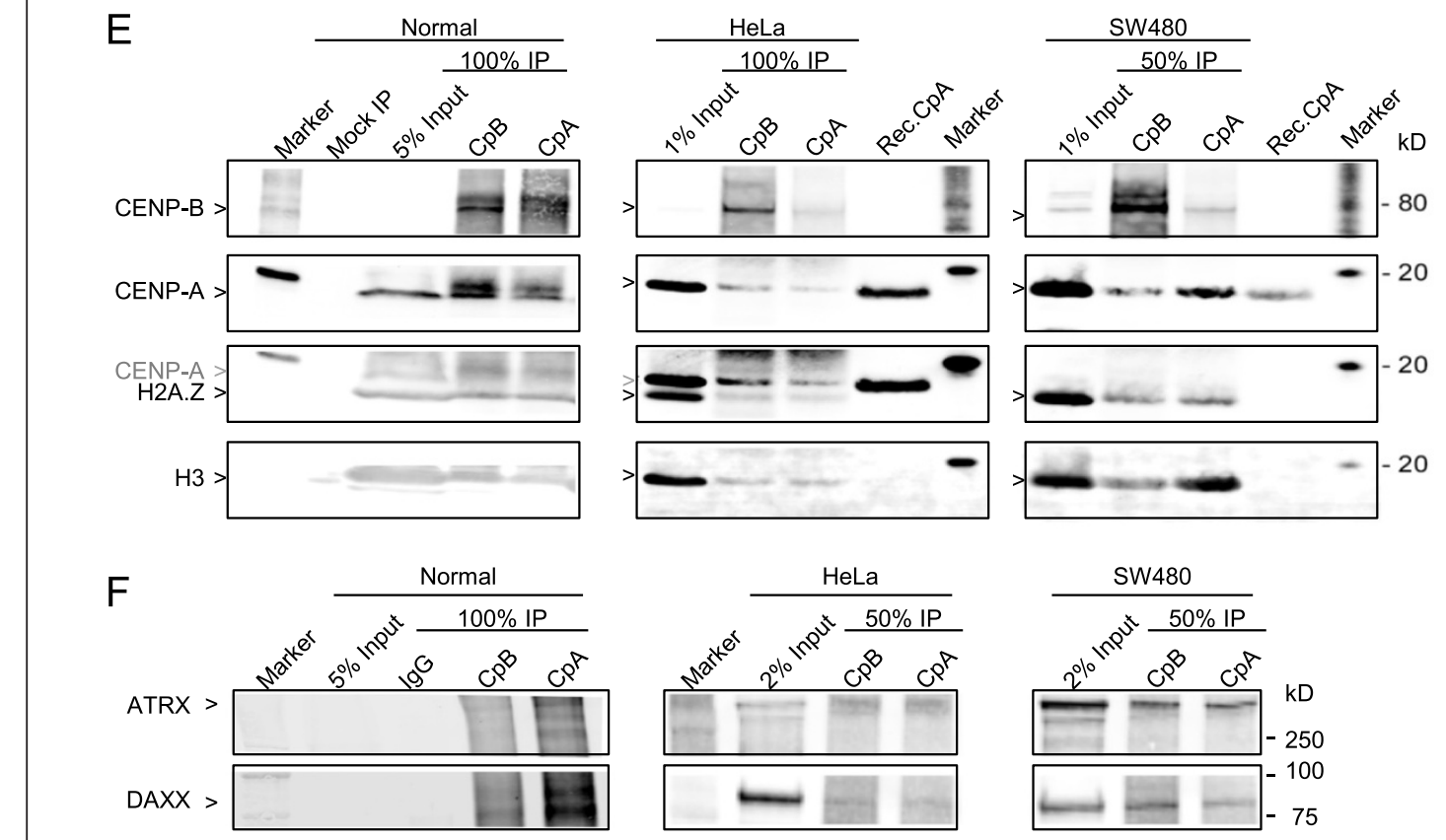

Figure 1 (See legend on next page.) 
(See figure on previous page.)

Figure 1 CENP-A is overexpressed in colon cancer SW480 cells, and associates with H3, ATRX, and DAXX. (A) Upper panel: Western blot (WB) analysis of total nuclear CENP-A, HJURP, ATRX, and DAXX, relative to core histone H4 across cell lines. Lower panel: quantification of CENP-A protein expression standardized to normal colon (replicate data from Table 1), error bars = SEM. (B) Upper panel: semi-quantitative PCR analysis of CENP-A mRNA expression in normal and SW480 cells in three replicates. Lower panel: quantification of the CENP-A mRNA expression normalized to $\beta$-actin from four experiments, error bars = SEM. (C) Scheme depicting strategy to separate centromeric from ectopic CENP-A nucleosomes and subsequent experiments performed with each fraction. (D) Micrococcal nuclease (MNase) ladders of input chromatin used subsequently in the primary CENP-B chromatin immunoprecipitation (ChIP) for normal, HeLa and SW480 cell lines demonstrates that mostly mono-, di-, and tri-nucleosomal arrays are present in the input chromatin. Slight variations in digestibility derive from intrinsic variability in the different cell lines' biology. (E) WB slice panels show CENP-B, CENP-A, H2A.Z, and H3 protein analysis from CENP-B IP and sequential CENP-A IP from normal, HeLa, and SW480 cells. Mock immunoprecipitation (IP) indicates control immunoprecipitation with nonspecific IgG. Recombinant CENP-A (Rec. CpA) was used as a detection specificity control. Gray CENP-A arrow in third row indicates a band that was already present prior to H2A.Z probing. Data quantification is provided in Table 2. (F) WB for ATRX and DAXX in normal, HeLa, and SW480 CENP-B IPs versus ectopic CENP-A IPS (data summarized in Table 2).

enrichment was sufficient to examine potential differences in composition and structure using biochemical and nanomolecular tools [36]. We also performed mock IPs to ensure that background levels of histones sticking to immune-beads could be factored in for each experiment that followed. The resultant sets of IPs were then resolved on high-resolution protein gels and probed for CENP-B, CENP-A, H2A.Z, and H3 by quantitative twocolor fluorescent WB. We observed a significant fraction of ectopic CENP-A present in normal colon cells, but relatively inefficient CENP-B pre-clearing (most likely due to a low abundance of extracted protein from that cell line) made the interpretation difficult (Figure $1 \mathrm{E}$ and Table 2). In contrast, CENP-B pre-clearing of nuclear extracts from HeLa and SW480 cancer cells was robust. Six- to seven-fold enrichment of CENP-B was observed in the CENP-B IP compared to the sequential CENP-A IP, indicating efficient centromeric chromatin depletion, leaving behind a pool of non-CENP-B associated CENP-A nucleosomes (Figure 1E and Table 2). The sequential CENP-A IP demonstrated a 3-fold enrichment of ectopic CENP-A nucleosomes compared to the centromeric fraction in SW480 cells, which constituted a 10-fold increase in comparison to HeLa, wherein ectopic CENP-A is depleted with regard to the centromeric fraction (3.02 versus 0.32 enrichment for SW480

Table 1 CENP-A, ATRX and DAXX are overexpressed in colorectal cell lines

\begin{tabular}{ccccc}
\hline Cell Line & CENP-A $^{\mathbf{a}}$ & HJURP $^{\mathbf{a}}$ & ATRX $^{\mathbf{a}}$ & DAXX $^{\mathbf{a}}$ \\
\hline Normal colon & 1 & 1 & 1 & 1 \\
DLD1 & $0.57 \pm 0.12$ & $2.19 \pm 0.73$ & $9.40 \pm 1.25$ & $1.22 \pm 0.12$ \\
HeLa & $1.26 \pm 0.09$ & $1.55 \pm 0.55$ & $5.22 \pm 0.14$ & $2.07 \pm 0.07$ \\
HCT116 & $1.32 \pm 0.10$ & $2.89 \pm 0.95$ & $13.94 \pm 4.01$ & $3.66 \pm 0.15$ \\
HT29 & $1.35 \pm 0.11$ & $4.69 \pm 1.80$ & $19.05 \pm 8.10$ & $3.18 \pm 0.15$ \\
SW480 & $1.75 \pm 0.23$ & $1.24 \pm 0.25$ & $22.40 \pm 3.91$ & $2.80 \pm 0.22$ \\
\hline
\end{tabular}

${ }^{\mathrm{a}}$ Fold-changes in each protein (CENP-A, HJURP, ATRX and DAXX) were calculated as the ratio of that protein $/ \mathrm{H} 4$ divided by ratio of the same protein $/ \mathrm{H} 4$ in normal colon cells. Data represents 3 replicates. and HeLa, respectively). Although no appreciable increase in H2A.Z was seen in the ectopic fraction of CENP-A, a threefold enrichment of canonical histone H3 in ectopic CENP-A IP was observed in SW480 compared to HeLa or normal colon cells. These data suggested co-occupancy or increased proximity of $\mathrm{H} 3$ and CENP-A in colorectal cancer cells (2.91 versus 0.98 H3 enrichment for SW480 and HeLa, respectively).

A recent study has reported that artificially overexpressed tagged CENP-A associates with the H3.3 chape rone DAXX in HeLa cells [24]. Since both, ATRX and DAXX, were overexpressed in HeLa and SW480 cells relative to normal (Figure 1A), we next investigated association of these chaperones with centromeric and ectopic CENP-A IPs from normal colon, HeLa, and SW480 cells. We noted a strong association between these chaperones and CENP-A in colorectal cancer cells (Figure 1F, Table 2). In contrast to a recent report demonstrating that artificially overexpressed CENP-A relies on DAXX/ATRX to associate at ectopic locations, we were unable to conclude that there was specific enrichment exclusive to the ectopic CENP-A fraction,

Table 2 Protein levels of CENP-A, CENP-B, H2A.Z, H3, ATRX, and DAXX in normal and cancer cell lines

\begin{tabular}{lccc}
\hline & Normal & HeLa & SW480 \\
\hline $\begin{array}{l}\text { CpB fold enrichment } \\
(\text { CpB IP/seq. CpA IP) }\end{array}$ & 1.67 & 5.90 & 7.59 \\
$\begin{array}{l}\text { Ectopic CpA fold enrichment } \\
\text { (Seq. CpA IP/CpB IP) }^{\mathrm{a}}\end{array}$ & 0.54 & 0.32 & 3.02 \\
$\begin{array}{l}\text { H2A.Z fold enrichment } \\
(\text { Seq. CpA IP/CpB IP) }\end{array}$ & 0.87 & 0.87 & 1.08 \\
$\begin{array}{l}\text { H3 fold enrichment } \\
(\text { Seq. CpA IP/CpB IP) }\end{array}$ & 1.00 & 0.98 & 2.91 \\
$\begin{array}{l}\text { ATRX fold enrichment } \\
(\text { Seq. CpA IP/CpB IP) }\end{array}$ & & & \\
$\begin{array}{l}\text { DAXX fold enrichment } \\
(\text { Seq. CpA IP/CpB IP) }\end{array}$ & - & 1.06 & 0.81 \\
\hline
\end{tabular}

${ }^{\mathrm{a}}$ Fluorescent western blot signals from Figure $1 \mathrm{E}$ and $\mathrm{F}$ were quantified on Odyssey Li-Cor, background-corrected, and input-adjusted fold-ratios between immunoprecipitations (IPs) were calculated as indicated. 
but rather noted both centromeric and ectopic CENPA fractions associated with these transcription-coupled chaperones.

These results outline three distinguishing characteristics of the 'high' CENP-A state in human cells: increased association of CENP-A with H3.3 chaperones ATRX and DAXX, increased interaction of canonical H3 with ectopic CENP$\mathrm{A}$, and an abundance of the ectopic CENP-A fraction.

\section{Ectopic CENP-A nucleosomes have altered conformations} In vivo, CENP-A and $\mathrm{H} 3$ do not mix within single nucleosomes [37]. Given the association of ectopic CENP-A and H3 above, we were curious whether such nucleosomes, or their chromatin fibers, might present an alteration of nucleosomal features. To this end, we turned to highresolution microscopy. In an extensive series of studies using AFM coupled to other biochemical assays, we have previously shown that in contrast to in vitro reconstituted recombinant CENP-A nucleosomes, which are octameric and generally indistinguishable from $\mathrm{H} 3$ nucleosomes [38-41], CENP-A nucleosomes purified from native human centromeres from HeLa or HEK cells, display smaller dimensions $[42,43]$, and attain a stable octameric height only at specific points of the human cell cycle [44]. Therefore, we next used AFM to measure native nucleosomal dimensions of ectopic versus centromeric and recombinant CENP-A nucleosomes.

In agreement with previously published work, native bulk nucleosomes observed on extracted chromatin arrays are exclusively octameric, averaging $2.5 \mathrm{~nm}$ in height (Figure 2, lowest panel, gray, AFM data summarized in Table 3). Furthermore, in vitro reconstituted H3(Figure 2, second panel from bottom, yellow), or CENP-Anucleosomes (Figure 2, third panel from bottom, yellow), which are octameric $[38-41,45,46]$, both possess dimensions essentially identical to bulk nucleosomes (dotted red line denotes mean octameric values). In contrast, the majority of total CENP-A nucleosomes in SW480 possess diminutive dimensions, averaging $2.1 \mathrm{~nm}$ in height (Figure 2, second panel from top, blue). However, upon closer examination, we noted that total CENP-A nucleosomes from SW480 have a distinct second population, with sizes reminiscent of the larger fraction of the stable octameric state (Figure 2, second panel from top, righthand tail highlighted in red). Indeed, upon depleting centromeric CENP-A nucleosomes using the CENP-B depletion strategy above (Figure $1 C$ ), ectopic CENP-A nucleosomal arrays derived from SW480 cells display a broad height distribution with an overall average slightly smaller than bulk octamers (2.46 nm, Figure 2, top panel, red; Table 3). This broader height distribution is most likely due to partial contamination of the ectopic fraction with the centromeric CENP-A nucleosomes originating from alpha satellite arrays lacking CENP-B boxes, as mentioned above.

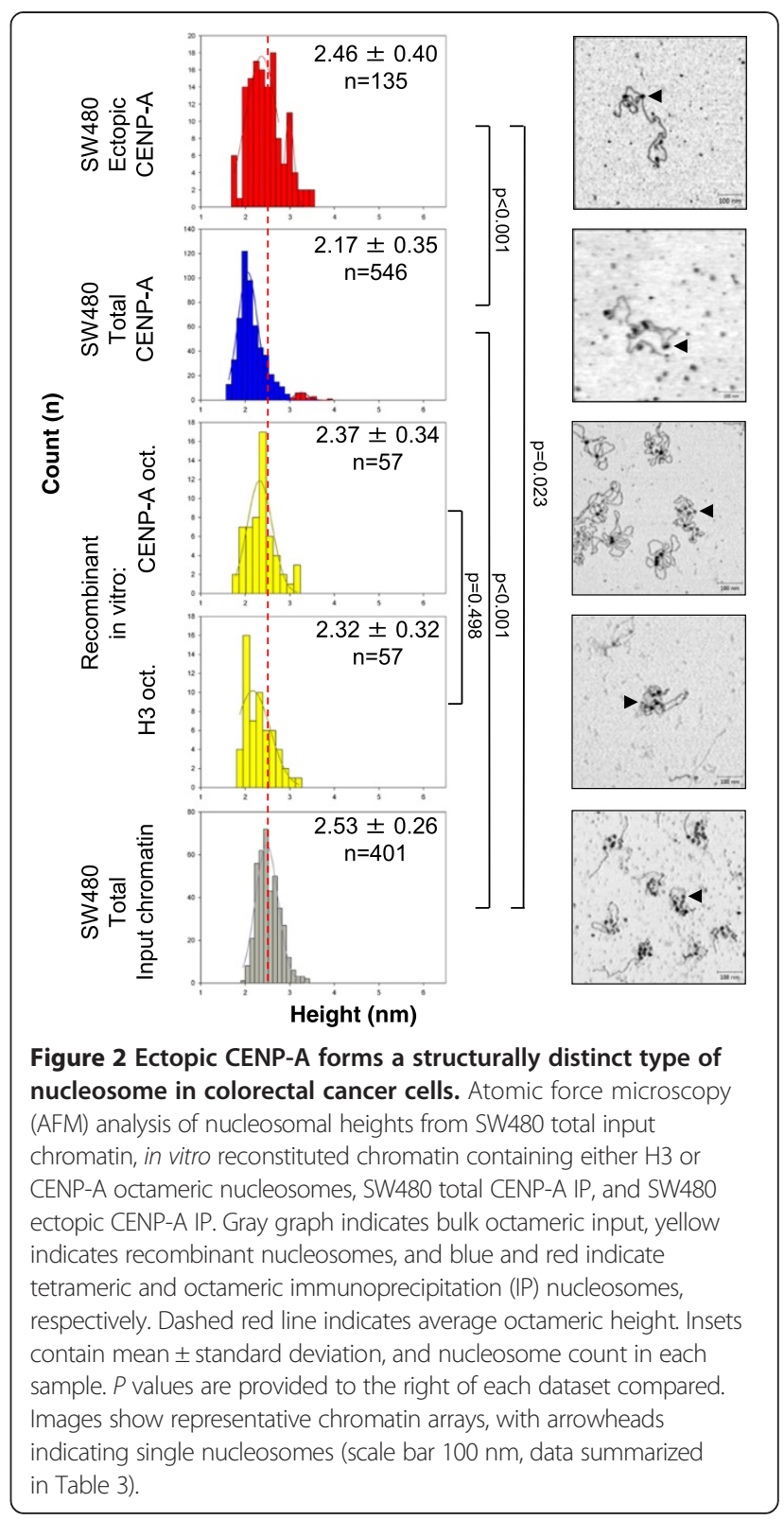

These data indicate that two distinct populations of CENP-A nucleosomes co-exist in colorectal cancer cells: one that contains diminutive features similar to that previously reported from native centromeres, and another that closely mimics the stable H3 or CENP-A octameric nucleosome in vitro.

\section{Ectopic CENP-A hotspots localize to DNase I hotspots and transcription factor binding sites}

We were curious to understand where ectopic CENP-A nucleosomes such as those above (Figures 1E, F and 2) might reside in the genome. Therefore, we amplified the nucleosomal DNA contained within SW480 CENP-B-associated centromeric and ectopic CENP-A nucleosomes, and used 
Table 3 Ectopic CENP-A nucleosomes are stable octamers

\begin{tabular}{lccccc}
\hline & $\begin{array}{c}\text { SW480 bulk } \\
\text { chromatin (n) }\end{array}$ & $\begin{array}{c}\text { Recomb. H3 } \\
\text { octamer (n) }\end{array}$ & $\begin{array}{c}\text { Recomb. CENP-A } \\
\text { octamer (n) }\end{array}$ & $\begin{array}{c}\text { SW480 total } \\
\text { CENP-A (n) }\end{array}$ & $\begin{array}{c}\text { SW480 ectopic } \\
\text { CENP-A (n) }\end{array}$ \\
\hline Height $^{\mathbf{a}}(\mathbf{n m})$ & $2.53 \pm 0.26(401)$ & $2.32 \pm 0.32(57)$ & $2.37 \pm 0.34(57)$ & $2.17 \pm 0.35(546)$ & $2.46 \pm 0.40(135)$ \\
Diameter $^{\mathbf{b}}(\mathbf{n m})$ & $13.8 \pm 1.4(401)$ & $12.1 \pm 1.4(20)$ & $10.6 \pm 1.4(20)$ & $14.1 \pm 2.9(546)$ & $14.5 \pm 3.0(135)$ \\
\hline
\end{tabular}

AFM measurements of aheight and ${ }^{b}$ diameter data of ectopic versus centromeric or recombinant CENP-A nucleosomes provided as average \pm standard deviation, with number of particles measured indicated in parenthesis. On average, each type of experiment has three replicates.

these two types of DNA in a co-immunofluorescence in situ hybridization (co-FISH) experiment against human metaphase chromosomes. As expected, CENP-B-associated nucleosomal DNA (in green) hybridizes almost exclusively to centromeres (Figure 3A). In contrast, ectopic CENP-A nucleosomal DNA (in red) hybridizes to chromosome arms (Figure 3A), illustrating the effectiveness of the CENP-B depletion strategy. This interesting distribution prompted us to generate a genome-wide map of ectopic CENP-A nucleosome residency in the genome. In order to achieve this, we performed high-throughput genomewide sequencing using exclusively the gel-purified mono-nucleosomal fraction from thoroughly MNase digested chromatin from Mock IP DNA, or ectopic CENP-A nucleosomal DNA from normal colon, HeLa, and SW480 lines. The mono-nucleosomal fraction was first assessed using high-resolution Bio-Analyzer chips (Figure $3 \mathrm{~B}$ and $\mathrm{C}$ ). Whereas, no detectable DNA could be seen in the mock IP, centromeric CENP-A IPs from either HeLa cells or SW480 cells, using the classical anti-centromere antibody (ACA) (first used to identify CENP-A in human cells by the Earnshaw lab, (39)), yield two species: one at approximately $120 \mathrm{bp}$, and the other at approximately $170 \mathrm{bp}$ (Figure 3C-E). The smaller species is consistent with previously published data for centromeric CENP-A nucleosomes (24, 38, $40,43$ to 50$)$. In contrast, ectopic CENP-A mononucleosomes contain DNA fragments ranging from 125 to $164 \mathrm{bp}$ of DNA (Figure $3 \mathrm{~B}$ and $\mathrm{D}$ ), greater than the 120 bp present in the CENP-A octameric crystal structure [39], or the 100-120 bp wrapping previously demonstrated to exist in vivo for native centromeres of yeast [47-49], Drosophila [42,50] or human cells [24,43,44]. As suggested by the AFM data above (Figure 2), these DNA data support the possibility that ectopic CENP-A nucleosomes contain distinctive structural features.

Sequencing of the mononucleosomal fraction obtained from chromatin input samples from each cell line confirmed equal and robust genomic representation in the extracts, which were comparable to other ENCODE data sets (Table 4). Reassuringly, mock IP ChIP-seq performed to rule out potential background signal identified a very small number of weak background-related hotspots (approximately 200). Furthermore, correlation analyses of replicates for normal colon, HeLa, and SW480 ectopic CENP-A ChIP-seq each demonstrated excellent concordance, with an $\mathrm{r}^{2}>0.9$ for each set of replicates (Figure 4A). From the pooled replicate concordant data, we next determined statistically significant, input-adjusted tags representing true ectopic CENP-A 'hotspots' in the genome, at a stringent false discovery rate (FDR) of $0.1 \%$. This method yields a robust view of CENP-A occupancy after accounting for copy number variation often found in cancer genomes. Contrary to our expectation that CENP-A would be found exclusively at centromeres or heterochromatin, ectopic CENP-A hotspots localize to noncentromeric loci in normal colon, HeLa, and SW480 cells (Figure 4B, left panel). Indeed, the main difference was the number of hotspots found in each cell line, which generally corresponded to the overall level of CENP-A expression: whereas in normal colon cells, there are approximately 450 ectopic CENP-A hotspots, in HeLa cells there is a twofold increase to approximately 950, and in SW480 cells there is an almost sixfold increase over normal colon to approximately 2,850 hotspots (Figure 4B, left panel). These hotspots do not arise from background signal, as only a tiny fraction of the mock IP-hotspots correlated with any of the ectopic CENP-A hotspots above (Figure 4B, left panel).

To investigate the nature of ectopic CENP-A hotspots, we next classified them with respect to known genomic and epigenetic features. Irrespective of the difference in the total number of hotspots, a sizeable portion of ectopic CENP-A was found at gene loci, with 23\%, 38\%, and $44 \%$ of ectopic hotspots at genes in HeLa, SW480, and normal colon cells, respectively (Figure 4B, right panel for histogram, and Additional file 1 contains the dataset of all hotspots discovered). Thus, CENP-A presence at genes seems to be a common feature, as it was found in all cell lines examined, with a significant fraction of those sites present at promoters of genes (7\%, 15\%, and 34\% in HeLa, SW480, and normal colon cells, respectively). Indeed, CENP-A enrichment at promoters is statistically significant in SW480 compared to HeLa cells (Fisher's exact test $P$ value: 0.0174 ), suggesting that colon cells tend to accumulate CENP-A at open chromatin regions (specific examples are shown in Figure 4C).

In the experiments above, we noted that the trans cription-coupled chaperones ATRX and DAXX are overexpressed in SW480 cells (Figure 1A), whereas levels of the CENP-A chaperone HJURP, which normally restricts 


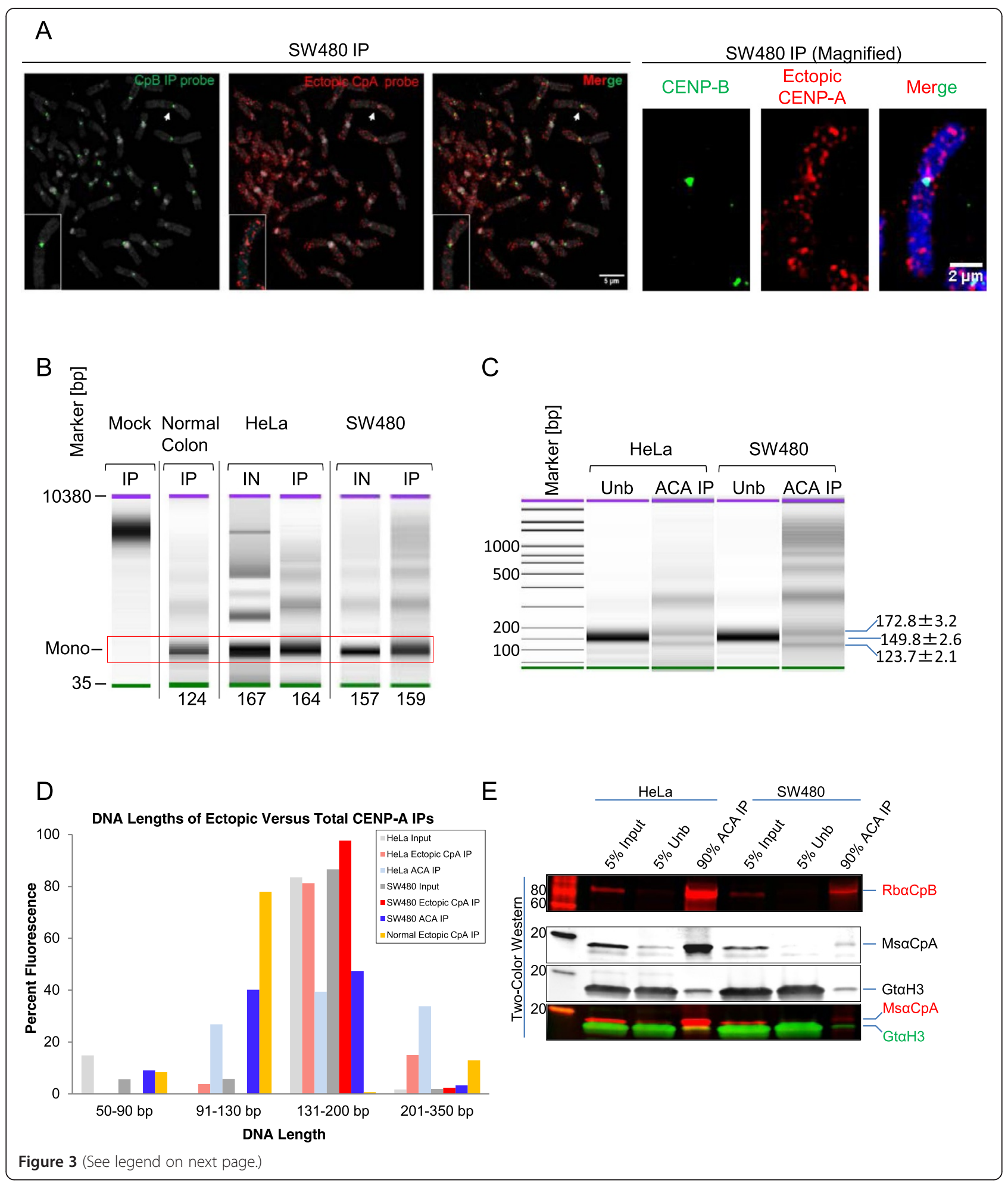


(See figure on previous page.)

Figure 3 Distribution and analysis of nucleosomal DNA associated with ectopic or total CENP-A immunoprecipitation. (A) Fluorescent in situ hybridization showing location of the DNA isolated from CENP-B and ectopic CENP-A immunoprecipitations. DNA isolated from either CENP-B (green) or ectopic CENP-A IP (red) was used to generate fluorescent in situ hybridization (FISH) probes and hybridized to metaphase chromosomes. Chromosome indicated by white arrow is shown magnified in the right panel. Blue/grey - DAPI, scale bars: 5 um (left panel) and $2 \mu \mathrm{m}$ (right panel). (B) High-resolution Bio-Analyzer DNA chips show no detectable mononucleosomal DNA in Mock immunoprecipitation (IP) and demonstrate that ectopic CENP-A nucleosome-associated DNA is octameric in size in normal colon, HeLa, and SW480 cells, ranging from 124 to 164 bp in length. (C) As above, indicating the size of nucleosome-associated DNA isolated from HeLa and SW480 cells by IP with anti-centromere antibodies (ACA) serum. (D) High-resolution Bio-Analyzer analysis of mononucleosomal DNA values for input, ectopic CENP-A nucleosomes (from Figure 1E) and centromere-specific CENP-A nucleosomes that were purified with ACA serum (from Panel E below). DNA lengths below 350 bp were binned into four categories, and plotted by percentage of total fluorescence (pg/uL). (E) Two-color WB analysis of CENP-A and H3 protein levels from HeLa and SW480 isolated by IP using ACA serum.

CENP-A to centromeres [23,31,32,51,52], generally did not correlate with increased CENP-A levels. We wondered whether ectopic CENP-A accumulation at promoters is linked to HJURP presence. Therefore, we performed HJURP IPs from cross-linked chromatin, using the CENP-B depletion strategy as above (Figure $1 \mathrm{C}$ ), followed by high throughput sequencing analysis to unveil potential sites of ectopic HJURP localization. We were unable to obtain robust ectopic HJURP enrichment. Fewer than 300 HJURP hotspots were detected in SW480 cells (Figure 4D, Additional file 1 for list of HJURP hotspots). Although $36 \%$ of the 942 HeLa CENP-A hotspots correlate with HeLa HJURP sites, only 5\% of SW480 CENP-A hotspots colocalize with SW480 HJURP sites (Figure 4D). Such paucity of noncentromeric HJURP sites overlapping with ectopic CENP-A sites in SW480 is consistent with HJURP's primary documented role as a centromeretargeted chaperone, and would support the hypothesis that overexpressed CENP-A can co-opt alternative chaperone pathways to accumulate at genes, as has recently been shown for forced overexpression of CENPA in human cells [24].

If CENP-A is indeed co-opting accessibility pathways to accumulate at genes, we hypothesized that chromatin accessibility might play a role in ectopic CENP-A localization. To test this, we turned to the classical DNase I nuclease hypersensitivity assay [53,54] combined with high throughput deep sequencing [55] to pinpoint with base-pair accuracy the locations of

Table 4 Genome coverage of chromatin input samples from normal colon, HeLa, and SW480

\begin{tabular}{ccc}
\hline Cell line & Number of reads & Percent genome coverage (\%) \\
\hline Normal colon $^{\mathbf{a}}$ & 25623102 & 60.175 \\
HeLa - rep 1 $^{\mathbf{a}}$ & 15153407 & 35.693 \\
HeLa - rep 2 $^{\mathbf{a}}$ & 25383705 & 59.401 \\
SW480 - rep 1 $^{\mathbf{a}}$ & 17372957 & 37.986 \\
SW480 - rep 2 $^{\mathbf{a}}$ & 17092081 & 48.774 \\
\hline
\end{tabular}

Chromatin input samples ${ }^{\text {a }}$ were analyzed by high-throughput sequencing and aligned to reference human genome 'hg19'. This data was used for input-adjustment of chromatin immunoprecipitation (ChIP)-seq samples. transcription-factor bound chromatin in SW480 and HeLa cells. (Normal colon cells were present in too low density for us to reliably assess DHS sites in those cells). To release hypersensitive chromatin, we performed very light DNase I digestion of either SW480 or HeLa nuclei following established protocols [56]. DHS fragments (ranging from 50 to $350 \mathrm{bp}$ ) float on top of sucrose gradients, separating them from the rest of the longer DNAs, which originate from the chromatinbound fraction. Purified DHS fragments were then subjected to deep sequencing (Figure 5A), thus generating a genome-wide distribution map of DHS.

As expected, the vast majority of DHS enrich primarily at promoters in HeLa and SW480 cells (Figure 5B, right panel shows histograms, and Additional file 1 for a list of DHS), and overlap completely with the compendium of aggregated DHS clusters identified by the ENCODE project for 129 human cell lines (Figure 5C). DHS identified in our data sets included promoters of housekeeping genes, oncogenes, and tumor suppressor genes (Additional file 1 for list of all DHS, examples in Figure 5D). For example, the $M y c$ gene, a known regulator atop a cascade of tumor effector proteins [57], has a large DHS site astride its promoter in SW480 cells (Figure 5D). Indeed, the gene encoding CENP-A itself has a strong DHS site upstream of its promoter specifically in SW480 cells but not in HeLa cells, providing a satisfying correlation between increased accessibility of the CENP-A gene promoter, and excess CENP-A mRNA (and subsequently, protein) present in SW480 cells (Figure 5D).

When comparing DHS hotspots to ectopic CENP-A sites, we observed that a large fraction of DHS tracks with ectopic CENP-A locations (Figure 5B, left and middle panels). Globally, about approximately 380 CENPA sites overlap with DHS sites in HeLa (Figure 5B, left and middle panels), whereas twice that number, approximately 740 SW480 CENP-A hotspots align perfectly with SW480 DHS.

A mechanistic question that arises from the correlation between ectopic CENP-A and DHS, was whether ectopic CENP-A creates DNase I sites once it binds to chromatin, 


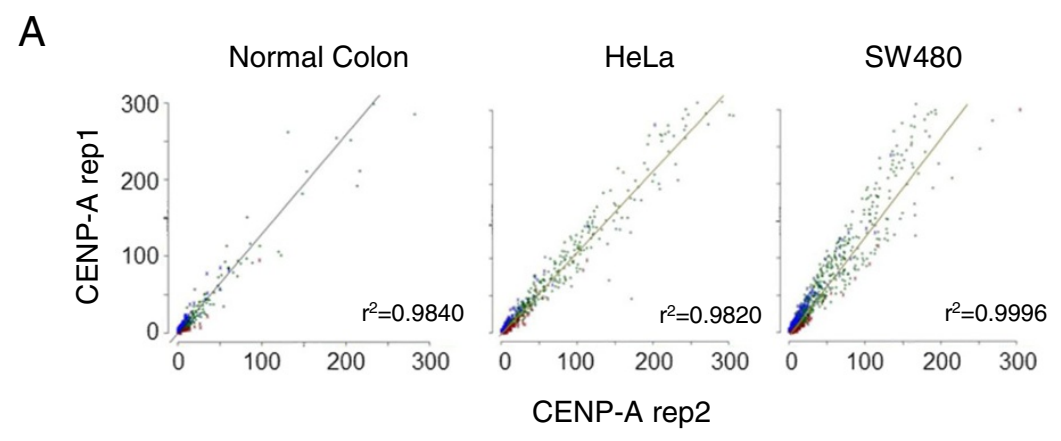

B
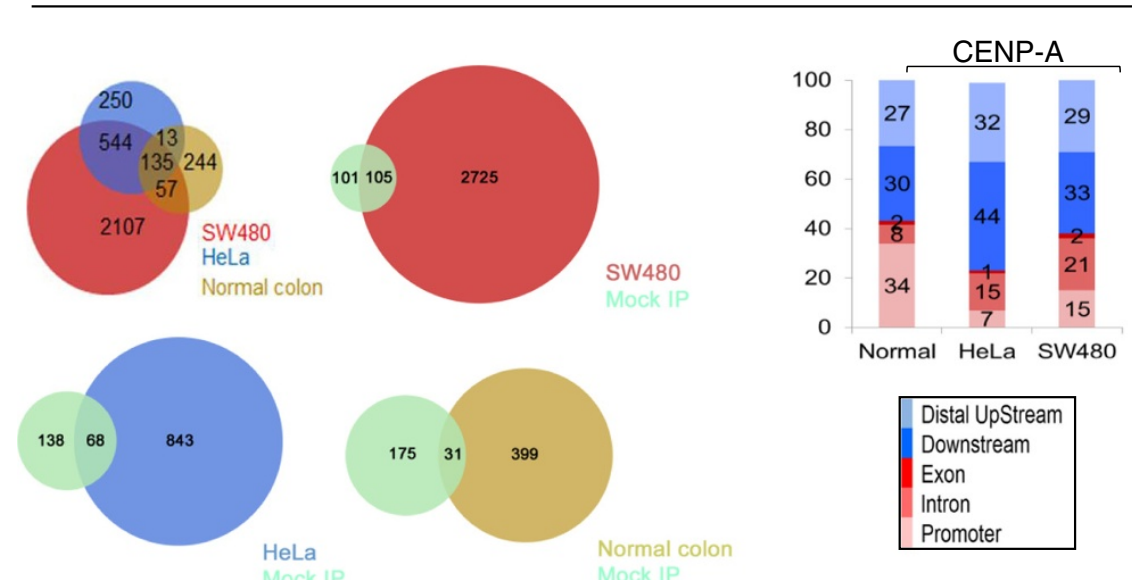

C
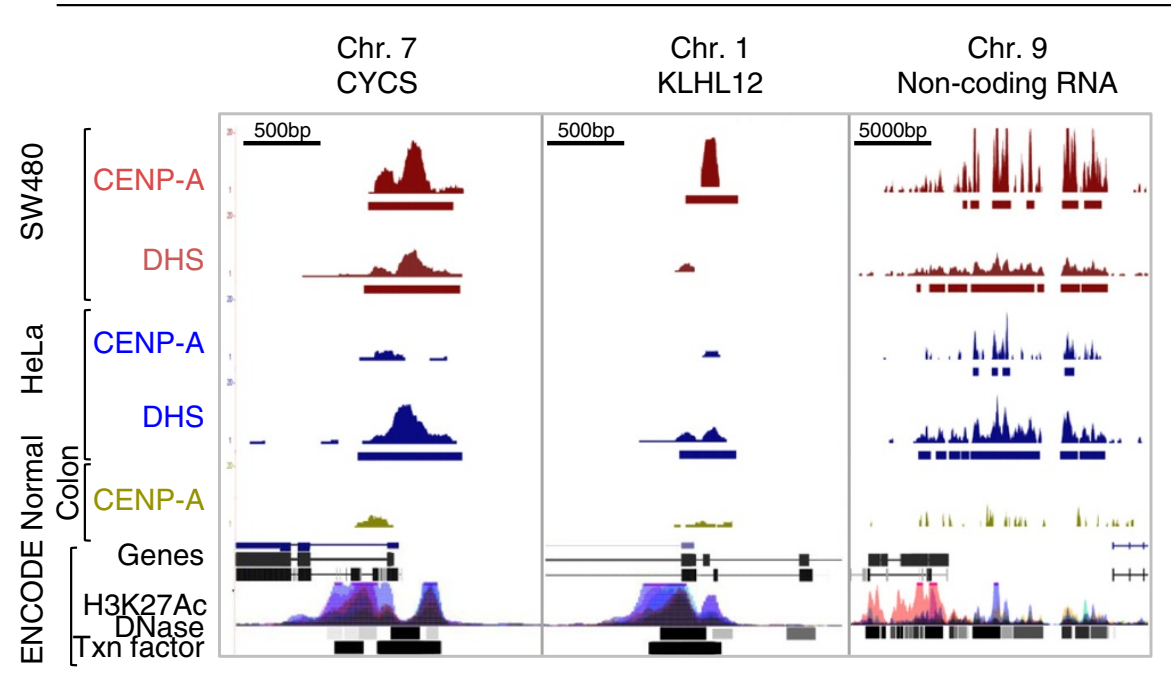

D

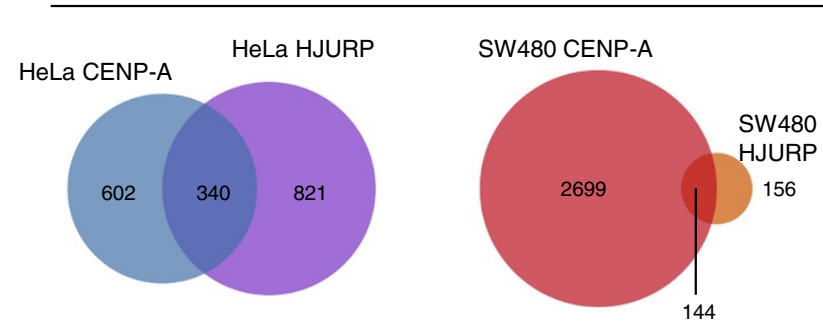

Figure 4 (See legend on next page.) 
(See figure on previous page.)

Figure 4 Genome-wide analysis of ectopic CENP-A demonstrates enrichment of CENP-A hotspots at DNase I hypersensitive sites. (A) Concordance analysis of chromatin immunoprecipitation (ChIP)-seq replicates of ectopic CENP-A IPs in normal colon, HeLa, and SW480 cells displays $r^{2}>0.9$, indicative of high reproducibility. (B) Left: distribution analysis of hotspots in normal, HeLa and SW480 cells; Venn diagrams of hotspots from SW480, HeLa, or normal colon cells versus Mock immunoprecipitation (IP). Right: Genomic location of hotspots from left panel shown as a percentage of total. Legend below indicates genomic location. Fisher's exact test was performed for comparison of HeLa and SW480 histograms: $P=0.0174$ (C) Genome browser snapshots of ectopic CENP-A localization depict representative examples of CENP-A and DHS hotspots at genes overlapping with clusters of DNase I sensitivity, H3K27Acetylation and Transcription factor binding in the ENCODE data. Scale bars are in the upper left corner of each snapshot. (D) Distribution of HJURP hotspots in HeLa and SW480 cells. Venn diagram demonstrates 30 to $40 \%$ of HJURP hotspots overlap with ectopic CENP-A hotspots, but the number of HJURP hotspots in SW480 is very low.

or whether such sites precede CENP-A occupancy. To this end, we compared CENP-A hotspots to aggregated genome-wide locations of DHS and transcription factor binding sites from 129 and 94 cell lines respectively (ENCODE project). From these comparisons it was apparent that pre-existing DNase I and transcription factor binding sites are striking determinants of ectopic CENP-A localization (Table 5). Approximately half of normal colon or SW480 CENP-A hotspots (61\% and $45 \%$, respectively) overlap with ENCODE DNase I clusters; and a majority of normal colon and SW480 CENPA hotspots (63\% and 48\%, respectively) overlap with transcription factor binding clusters found in a variety of cells (Table 5). This increase in overlap between SW480 CENP-A hotspots and our DHS analysis, compared to the ENCODE DHS data (from 26\% to 45\%), indicates that CENP-A can also localize to transient hypersensitive sites, which were not detected in our experiments but were captured in the vast compendium of DHS sites in the ENCODE data.

We were curious whether ectopic CENP-A locations had DNA sequence-specific features that might yield insights into what attracts CENP-A to them. Using the DNA consensus detection algorithm TOMTOM to detect motifs common amongst CENP-A hotspots, we discovered that CENP-A enriched sequences are not AT-rich, nor do they contain centromere-like repetitive DNA. Indeed, fewer than $20 \%$ of the hotspots contain Alu, LINE or SINE elements, and less than $0.01 \%$ of the hotspots contained centromeric consensus alpha satellite sequences (Table 6), suggesting the CENP-B depletion strategy was effective. Whether from normal colon, HeLa, or SW480, ectopic CENP-A hotspots contain CpG motifs (Figure 6A-B), and motifs associated with transcription factors, especially those of the zinc-finger and helix-turn-helix classes (Figure 6B-C). Together, the DHS and DNA motif data suggest that ectopic CENP-A accumulates at regions of high nucleosome turnover in the genome.

Ectopic CENP-A nucleosomes cluster at subtelomeric sites, including 8q24/Myc, in colorectal cancer cells and tumors In the genome-wide map of all CENP-A hotspots identified in this study, we noted a qualitative clustering of CENP-A hotspots in subtelomeric and pericentromeric regions (Figure 7 shows all chromosomes, Figure 8A focuses on one example, grey boxes denote clusters). Such regions have been previously associated with chromosomal breakpoints and translocations [58]. We chose one of these domains involving the cytoband $8 \mathrm{q} 24$ for further analysis, as it represents one of the most frequently rearranged regions in the cancer genome of many carcinomas and hematological malignancies [59,60]. Furthermore, this region has long been associated with tumorigenesis $[61,62]$, and with chromosome instability [63]. From previously published cytogenetic SKY/CGH maps, it is known that the $8 \mathrm{q} 24 / M y c$ locus is amplified and translocates to multiple chromosome partners in SW480 cells but not in normal colon cells [64].

The deep sequencing data uncovered a $30 \mathrm{MB}$ region of CENP-A and DHS co-enrichment on the 8q24/Myc locus in SW480, but not HeLa or normal cells. This enrichment was apparent even after correcting for copy number amplification of this locus (Figure 8B, see input-adjusted hotspots below the tag density tracks). This result was surprising, because although this region has been extensively studied, there are no extant reports of it containing unusual histone variants. Furthermore, large domains of CENP-A usually exist only in active centromeres, wherein they attract inner kinetochore proteins such as CENP-C, which connect CENP-A to the outer kinetochore during mitosis [65]. We tested whether CENP-C was enriched in the 8q24 region. Using CENP-A and CENP-C ChIP followed by quantitative PCR (qtPCR) for probes spanning this $30 \mathrm{MB}$ locus (primer locations indicated in Figure 8A), we observed robust enrichment of both CENP-A and CENP-C within the domain spanning the 8q24 locus (Figure 8C, qtPCR graph). We reasoned that a CENP$\mathrm{A} / \mathrm{CENP}-\mathrm{C}$ domain spanning $30 \mathrm{MB}$ should be visible by immunofluorescence. Therefore, we used a combination of 8q24-FISH and CENP-A-IF to visualize this region. To ensure the accuracy of detection, we first tested the $8 \mathrm{q} 24$ FISH probe on metaphase spreads from normal human lymphocytes. As expected, we observed two discrete subtelomeric signals per chromosome, for a total of $4 \mathrm{~N}$ per mitotic cell (Figure 8D, upper left panel). We next tested whether $8 \mathrm{q} 24$ was amplified and 


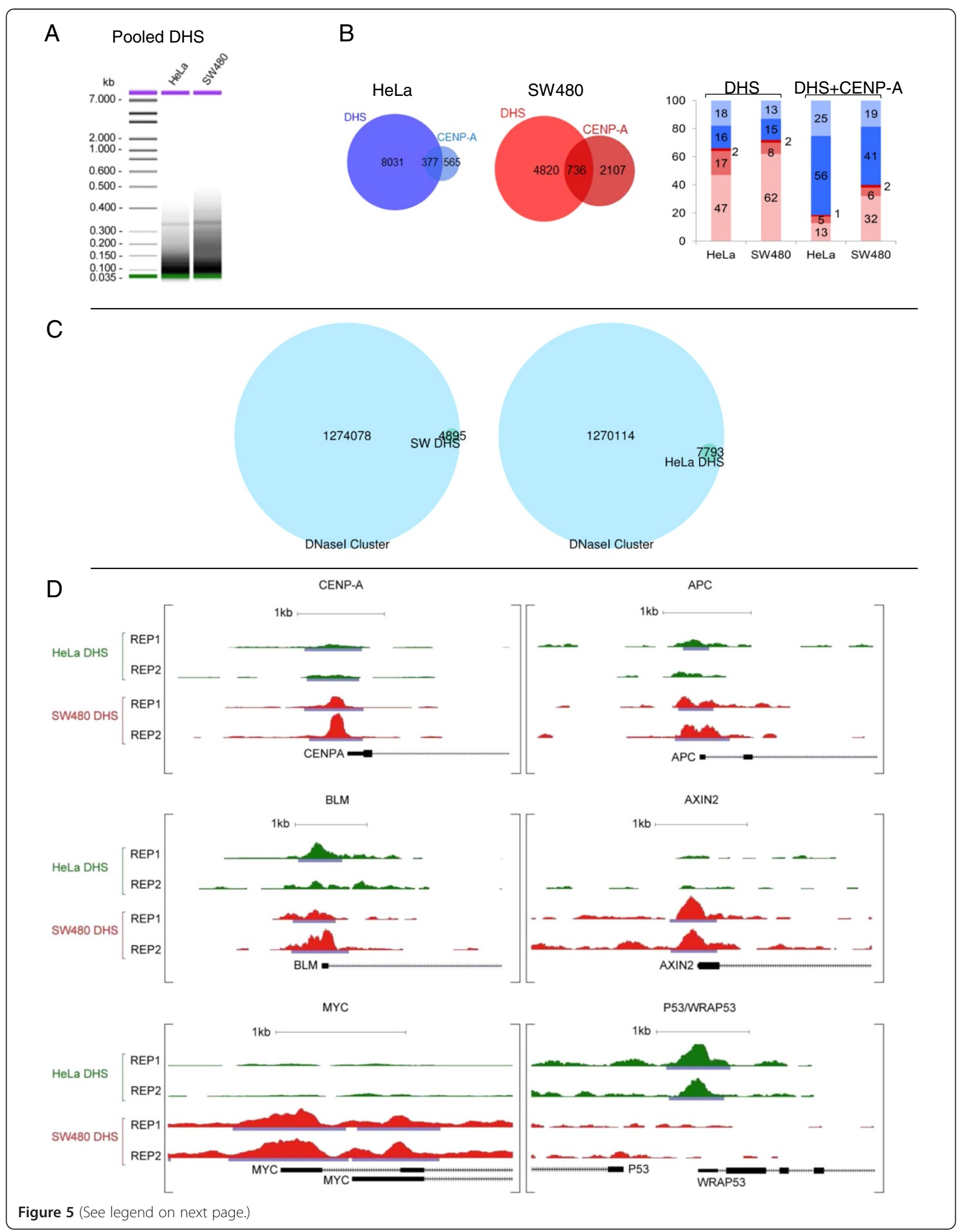


(See figure on previous page.)

Figure 5 DNase I hypersensitive sites (DHS) are enriched at promoters of oncogenes and tumor suppressor loci in the colorectal cancer genome. (A) Sucrose gradient purification of DHS fragments resolved on High-resolution Bio-Anaylzer gels before deep sequencing. (B) Left: distribution analysis and overlap between HeLa DHS and HeLa CENP-A; and SW480 DHS and SW480 CENP-A. Right: Genomic locations of CENP-A hotspots coinciding with DHS shown as a percentage of total, color-coded as in (B). (C) DHS identified in this study wholly belong to the large compendium of DHS identified by ENCODE in 129 cell lines. (D) Examples of DHS profiles for individual genes demonstrate that the promoters of some oncogenes are preferentially accessible in SW480 cancer cells. The gene for CENP-A itself has an increased DHS peak over its promoter in SW80 cells, correlating with increase in mRNA and protein levels for CENP-A in SW480 cells.

translocated in the cancer cells, as would be expected for this locus. Co-FISH for $8 \mathrm{q} 24$ and the native centromere 8 demonstrates one set of $8 \mathrm{q} 24$ signals originating from a subtelomeric location on chromosome 8 , as well as a number of additional signals emanating from translocated sites (Figure 8C, upper right panel).

Using a combination of either 8q24. FISH and CENP-A IF, or Myc FISH and CENP-A IF, we next tested whether CENP-A co-localizes to any of the signals of 8q24 in normal colon, HeLa, and SW480 cells. No correlation between 8q24 and CENP-A signals can be seen in normal colon, and very little can be seen in HeLa cells (Figure 8C-D, three lower left panels). In contrast, 8q24 co-localizes to a distinct CENP-A domain in 38-66\% of SW480 cells, when using either the $8 \mathrm{q} 24$ or $M y c$ probes, respectively (Figure $8 \mathrm{C}$, middle left panel, white arrows point to co-localized signals; Figure 8D, lower right panels; data are quantified in Table 7). Thus, in the colorectal cancer cell line possessing the highest amount of CENP-A protein (Figure 1A), CENP-A localizes to 8q24 in a large fraction of cells. Consistent with the qtPCR data (Figure 8C, first panel), CENP-C IF combined with 8q24 FISH demonstrates enrichment of CENP-C on one 8q24 locus (Figure $8 \mathrm{C}$, middle right panel).

We were intrigued by the presence of CENP-A/CENP$\mathrm{C}$ at the 8q24 locus in the SW480 colorectal cancer SW480 cell line, which was derived from a late stage colorectal tumor nearly 30 years ago [64]. We sought to understand how early in tumorigenesis CENP-A might mislocalize to $8 \mathrm{q} 24$. We acquired primary early and late stage colorectal tumors, as well as matched normal tissue from the same patients, and performed FISH/IF to test co-localization of CENP-A to $8 \mathrm{q} 24$. The co-IF/FISH data show that the $8 \mathrm{q} 24 / M y c$ locus is amplified in all four tumors, and that CENP-A domains are enriched on one of these $8 \mathrm{q} 24$ loci ranging from 33 to $78 \%$ of tumor cells, depending on the donor (Figure 8C, lowest set of panels for representative images of normal versus tumor, white arrow points to co-localization, quantification in Table 7). Thus, CENP-A occupancy of this locus is robust and occurs even in early stage tumors.

\section{Discussion}

In this report, we present a comprehensive examination of the histone variant CENP-A in colorectal normal and cancer cells, finding that ectopic CENP-A exists outside centromeres in human cells. Ectopic CENP-A tracks to two distinct types of domains: small regions found at promoters and accessible chromatin; and large domains found at sites of common chromosomal rearrangements. Our report yields a number of specific findings. First, CENP-A, which is innately overexpressed in cancer cells (Figure 1A-B, Table 1), associates with histone H3 (Figure 1E, Table 2), and shows increased association with transcription-coupled chaperones DAXX and ATRX (Figure 1F, Table 2). Second, ectopic CENP-A nucleosomes are stable octamers in configuration (Figure 2, Table 3), containing 125 to 165 bp of DNA (Figure 3B-D). Third, ectopic CENP-A nucleosomal tags are depleted in centromeric consensus satellite sequences (Table 6), and localize instead to unique noncentromeric locations in normal and cancer cell lines (Figure 3A). These nucleosomes occupy genes and promoters (Figure 4B-C), are HJURP-free (Figure 4D), and correlate primarily with hyper-accessible (DHS) chromatin (Figure 5, Table 5). Fourth, CENP-A/DHS ectopic sites co-occupy regions containing known transcription factor binding motifs (Figure 6, Table 5). Lastly, large clusters of CENP-A hotspots exist in regions spanning pericentric and subtelomeric regions specifically in colorectal cancer cells (Figures 7 and 8, Table 7). An example of such a cluster is at a segment of the $8 \mathrm{q} 24$ locus spanning the $M y c$

Table 5 Ectopic CENP-A is enriched at DNase I hypersensitive (DHS) sites and transcription factor binding sites

\begin{tabular}{lcccccc}
\hline CENP-A hotspots $^{\mathbf{a}}$ & Normal colon & $\%$ & HeLa & $\%$ & SW480 & \% \\
\hline DNase clusters $^{\mathbf{b}}$ & 273 & 60.80 & 247 & 26.22 & 1292 & 45.44 \\
Txn Factor ChIP $^{\mathbf{c}}$ & 285 & 63.47 & 255 & 27.07 & 1361 & 47.87 \\
\hline
\end{tabular}

Comparative analysis of ${ }^{2}$ CENP-A hotspots derived from normal colon, HeLa and SW480 cells compared to ENCODE data aggregates reveal a significant fraction of sites overlap with ENCODE ${ }^{b}$ DNase I clusters and ${ }^{c}$ transcription factor binding sites in the genome. Each column shows overlap in terms of number of sites or \% of total CENP-A sites. 
Table 6 Analysis of total sequence tags obtained from normal colon, HeLa and SW480 CENP-A immunoprecipitations (IPs) demonstrates they are not enriched in repetitive elements

\begin{tabular}{|c|c|c|c|c|c|c|}
\hline Tags $^{a}$ & Normal colon & $\%$ & HeLa & $\%$ & SW480 & $\%$ \\
\hline Alu & 334960 & 0.65 & 226475 & 0.65 & 216285 & 0.63 \\
\hline LINE & 10749901 & 20.81 & 6808429 & 19.52 & 6340827 & 18.53 \\
\hline SINE & 1034138 & 2.00 & 711621 & 2.04 & 700002 & 2.05 \\
\hline Centromeric $a$-satellite & 633 & 0.001 & 1163 & 0.003 & 3871 & 0.011 \\
\hline \# total tags & 51651054 & 100.00 & 34875940 & 100.00 & 34212787 & 100.00 \\
\hline
\end{tabular}

oncogene, which, even in relatively early stage tumors tested in this study, associates with CENP-A and CENP-C (Figure 8B-D, Table 7).

A number of avenues of investigation arise from our observations. Regardless of the absolute amount of ectopic CENP-A, in normal colon cells, and in the cancer cell lines examined, there is a connection between DHS/ transcription factor binding sites and ectopic CENP-A (Figures 5 and 6). That CENP-A can compete for regions linked to transcription was initially demonstrated in budding yeast, wherein CENP-A is reported to exist at barely detectable levels in a handful of genic promoters [49], which increases when CENP-A is artificially overexpressed [48]. Such CENP-A is continually targeted for subsequent proteolysis [23,52]. Earlier work has also demonstrated that artificial constitutive overexpression of CENP-A in Drosophila cells results in a gradual accumulation and slow removal of CENP-A from chromosome arms [22], possibly via association with the common histone chaperone RbAp48/p55 [66]. In vitro, common chaperones such as p55 and NAP-1 assemble CENP-A nucleosomes efficiently [41,66]. However, generally it has not been thought that such phenomena could occur in human cells, with many laboratories publishing studies using tagged/ overexpressed CENP-A as a marker for human centromeres. However, a recent report tracking artificially overexpressed human CENP-A has demonstrated that it can occupy ectopic sites, binds histone H3.3, contains octameric size DNA fragments, and is potentially chaperoned by ATRX and DAXX [24]. Indeed, in worms, which form holocentric centromeres that line the edges of chromosomes, normal amounts of CENP-A seed centromeric domains using regions of low nucleosome turnover [67]. Our report demonstrates that a subset of native human CENP-A binds $\mathrm{H} 3$, forms octameric height nucleosomes, which localize to accessible chromatin domains at promoters and transcription factor sites at low levels even in normal human colon cells. This process appears to be magnified in amplitude in colorectal cancer cell lines, where a significant fraction of ectopic CENP-A nucleosomes overlap with DHS and transcription factor binding sites (Figure 5 and 6). It is feasible that a default transcription-linked pathway exists to use trace amounts of CENP-A either promiscuously expressed at the wrong time (that is, not at the end of G2 [68]), or remnant after HJURP-dependent incorporation at centromeres is complete at mid-G1 [69]. Not mutually exclusive to this explanation is the interesting possibility that defects in the timing of CENP-A expression, or promiscuous binding of CENP-A to other chaperones, coupled to defects in proteolysis, might cumulatively conspire to permit increased CENP-A accumulation at transcription factor binding sites in cells.

\section{Conclusions}

A functional implication of stable CENP-A occupancy of promoters/DHS and its correlation with transcription factor binding sites is the potential link to gene expression changes reported in cancer cells. It is currently unknown if CENP-A is recruited by, or competes for transcription factor binding sites, either of which would be predicted to impact gene expression. Indeed, the DHS data demonstrate that many of the sites that attract CENP-A are already DHS and transcription factor binding sites, that is, high nucleosome turnover regions in a number of human cell lines. At the vast majority of genes in vivo, octameric $\mathrm{H} 3$ nucleosomes, with specific $\mathrm{N}$-terminal tail modifications, dominate the epigenetic regulatory landscape [70]. Ectopic CENP-A nucleosomes would lack known H3 N-terminal tail modifications, and could potentially circumvent traditional epigenetic regulatory cascades. Thus, the functional impact of CENP-A nucleosomes on pre-existing DHS sites, or on promoter architecture, remains an exciting avenue of research. Ongoing studies are focused on whether recruitment of transcriptional activator or repressor complexes is altered in the presence of ectopic CENP-A nucleosomes, and whether such events influence gene expression patterns specifically in the cancer context.

Our study also provides support for a potential role for CENP-A in chromosomal instability. Whereas various artificial overexpression studies over the past decade have clearly established CENP-A's ability to seed neocentromeres [17], this study provides a correlation between CENP-A and a defined chromosomal rearrangement at 


\section{A}
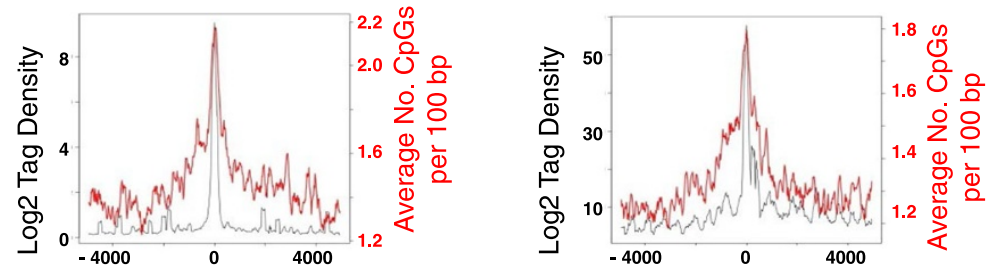

Coordinates from Center of Hotspots (bp)

Coordinates from Center of Hotspots $(\mathrm{bp})$

B
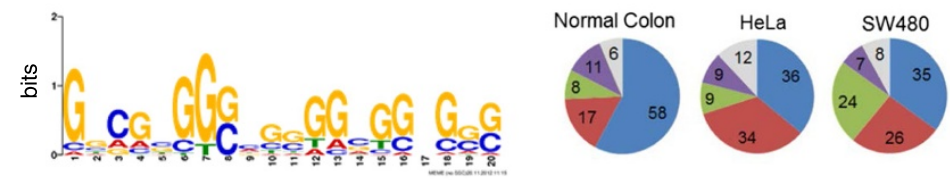

Zinc-coordinating Zippertrpe

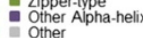

C

\begin{tabular}{|c|c|c|c|c|}
\hline \multicolumn{3}{|c|}{ Motif 1} & & Motif 3 \\
\hline \multicolumn{5}{|l|}{ T } \\
\hline Motif & P-Value & Sites & Predictions & Specific Function Predictions \\
\hline \multirow[t]{3}{*}{1} & \multirow[t]{3}{*}{$2.413 e-11$} & \multirow[t]{3}{*}{447} & \multirow[t]{3}{*}{20} & MF olfactory receptor activity \\
\hline & & & & $\begin{array}{l}\text { BP G-protein coupled receptor protein signaling } \\
\text { pathway } \\
\end{array}$ \\
\hline & & & & CC extracellular region \\
\hline \multirow[t]{3}{*}{2} & \multirow[t]{3}{*}{$8.479 e-06$} & \multirow[t]{3}{*}{283} & \multirow[t]{3}{*}{168} & MF transmembrane receptor activity \\
\hline & & & & BP cell surface receptor linked signaling pathway \\
\hline & & & & CC plasma membrane \\
\hline \multirow[t]{3}{*}{3} & \multirow[t]{3}{*}{$6.7 e-042$} & \multirow[t]{3}{*}{103} & \multirow[t]{3}{*}{895} & MF chromatin binding \\
\hline & & & & BP negative regulation of signal transduction \\
\hline & & & & CC transcription factor complex \\
\hline & & & - higleris? & ; CC = \\
\hline
\end{tabular}

Figure 6 DNA analysis of ectopic CENP-A hotspots demonstrates enrichment of CpG density and transcription factor binding motifs.

(A) Ectopic CENP-A associated DNA is moderately enriched in CpG motifs. Window shows CpG motifs enriched in a scanning 10 bp window from an overlay of all hotspots (B) Left: TOMTOM DNA Motif analysis of CENP-A hotspots in SW480 and HeLa cells. Right: Pie charts showing similarity of identified hotspots to known classes of transcription factor binding sites. Detailed data for analysis of hotspots can be found in Table 5. Additional file 1 contains the full list of hotspots, and a genome-wide overview is in Figure 7. (C) A list of other TOMTOM consensus motifs that correlate to the motifs identified in CENP-A hotspots includes chromatin effector proteins.

$8 \mathrm{q} 24$ in human cancer cells, which is absent in normal colon cells (Figure 8, Table 7). When normal human ES cells are challenged by induced DNA breaks, excess native CENP-A is rapidly mobilized, but does not localize to immediate break sites indicated by gammaH2A.X staining [71]. However, a recent study used osteosarcoma-derived U2OS cancer cells, in which an artificially induced break was shown to efficiently recruit overexpressed CENP-A:GFP [72]. Thus, depending on the timing of the break, and availability of free histones, CENP-A might enrich during subsequent steps of chromatin re-establishment following repair or translocations of amplified regions in cancer cells. An avenue of research that arises from these findings 


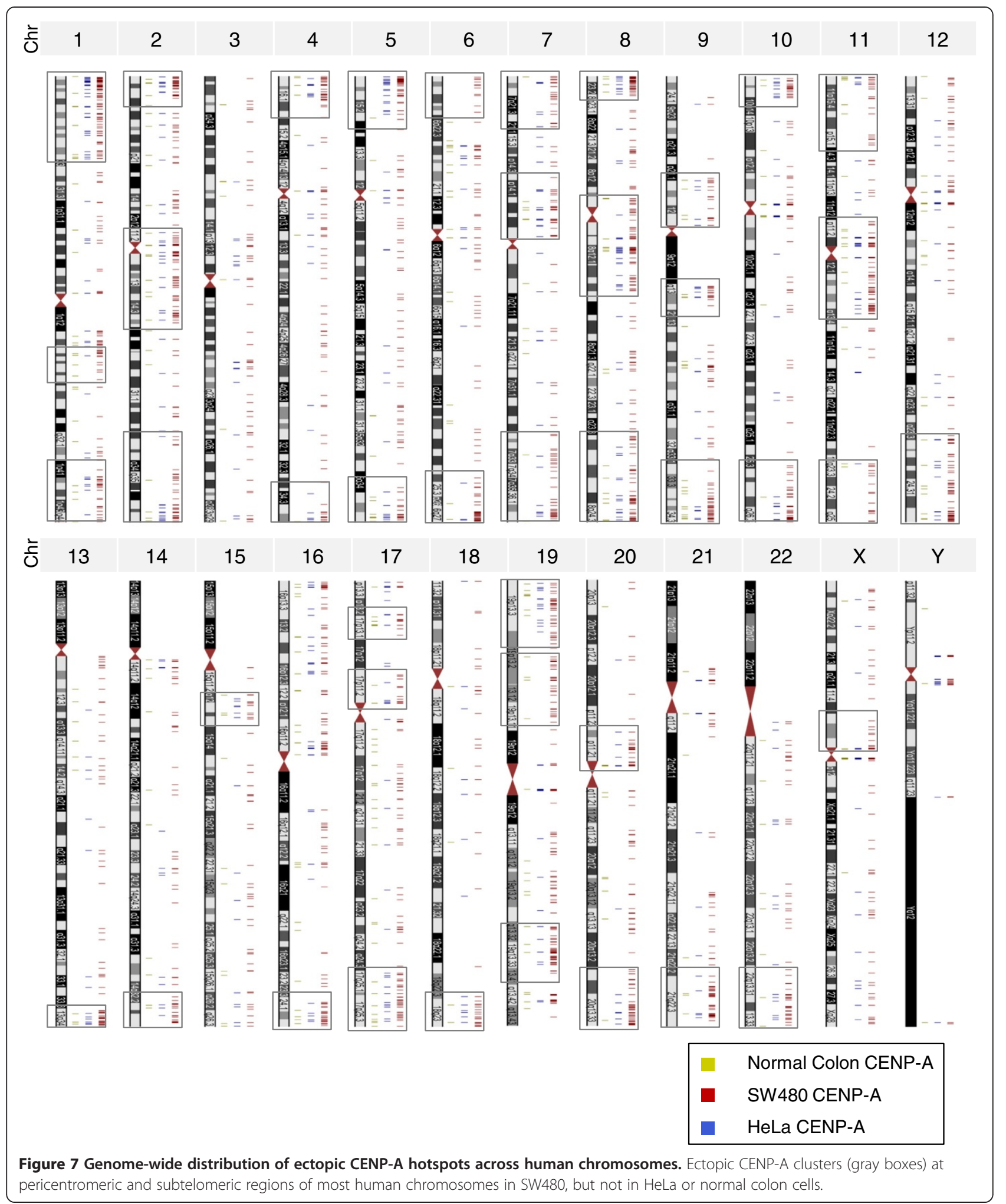

is elucidating the timing of CENP-A enrichment at breakpoints during tumorigenesis, and investigating its potential role in structural rearrangements of chromosomes in subtelomeric sites such as 8q24.
Increased levels of CENP-A expression have been reported in metastatic prostate, breast, lymphoma, lung and colorectal tumors. Consequently, our observations, combined with other recently published studies on 


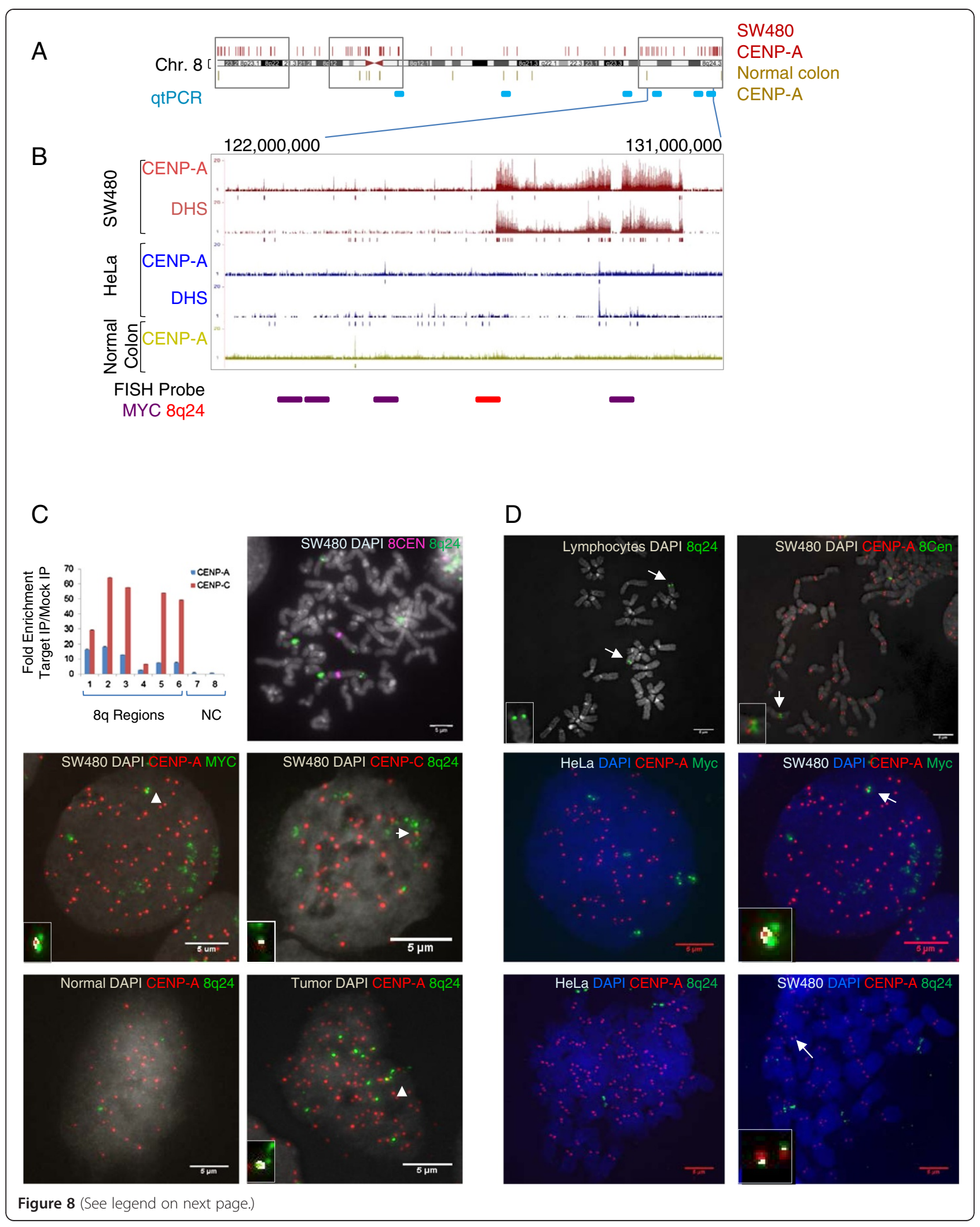


(See figure on previous page.)

Figure 8 Ectopic CENP-A clusters at a large domain at the subtelomeric 8q24/Myc locus in colorectal cancer cells and tumors. (A) CENP-A hotspots cluster (indicated by gray boxes, additional examples in Figure 7) at subtelomeric regions of chromosome 8 in SW480 cells, but not in normal colon cells. (B) Chromatin immunoprecipitation (ChIP)-seq profiles (tag density peaks) and input-adjusted hotspot analysis (vertical bars below each profile) demonstrate CENP-A distribution relative to input chromatin upon the 30 MB domain spanning the cytogenetic band 8q24 in SW480, HeLa, and normal colon cells (note that input tag density peaks reflect increased copy number of this region in SW480 cells, but hotspot analysis takes into account copy number variation). Base numbers above indicate the genomic location, and horizontal lines below the genome browser profile indicate position of fluorescent in situ hybridization (FISH) probes used for FISH/CO-IF in (C). (C) Upper left panel: qtPCR graph demonstrating CENP-A and CENP-C enrichment at the 8q24 locus in SW480 cells (positions of PCR primers are indicated in (A), negative control (NC) primers were selected from chromosomes 1 and 11 from regions with no CENP-A peaks based on ChIP-seq data). Upper right panel contains cytological analysis of metaphase chromosome spreads stained with FISH probe for 8q24 (in green), indicating amplification of this region in SW480 cells. One of these translocated 8 q24 loci (green) associates with CENP-A (red) (middle left panel) and the inner kinetochore protein CENP-C (red) (middle right panel). Combining FISH and IF in three primary colon tumors demonstrates that CENP-A (red) co-localizes with one of the amplified regions of 8q24/Myc (green) in the tumor (right bottom panel) but not in normal tissue (left bottom panel). White insets and arrowheads point to co-localization spots detected by Image J automated co-localization algorithm. Quantification is provided in Table 7. (D) Additional controls for the FISH/IF experiments in (C). First panel depicts FISH of 8q24 to metaphase spreads of normal human lymphocytes, demonstrating specific hybridization to 2 subtelomeric locations. Second panel depicts Co-IF/FISH of native centromere 8 and CENP-A on metaphase chromosome spreads in SW480 cells demonstrating that native centromere 8 still contains CENP-A and is active. Remaining panels demonstrate that CENP-A co-localizes to one of the amplified and translocated regions of 8q24/Myc in SW480 cells (right panels), but not in HeLa (left panels) cells. Quantification of this data is presented in Table 7. Merge of DAPI (blue or gray), 8q24 or Myc (green) and CENP-A (red) is indicated for each cell line at the top of each image. Automated co-localization analysis was performed using Image $\mathrm{J}$; white is indicative of co-localization shown as insets.

artificially induced hybrid CENP-A/H3 nucleosomes [24,73], have implications for accumulation of downstream epigenetic defects that arise during tumorigenesis.

\section{Methods}

\section{Cell culture}

All cell culture medium except epithelial cell medium was supplemented with $10 \%$ fetal bovine serum and $1 \mathrm{X}$ penicillin and streptomycin. Cell culture media DMEM was used for HeLa cells, RPMI for SW480 and DLD1, and McCoy's media for HCT116 and HT29. Epithelial cell medium was used to culture normal human colon epithelial cell (HcoEpiC). HcoEpiC cells are very slow growing, with the cell cycle lengths ranging from 36 to 90 hours depending on passage number.
Total nuclear proteins extraction

Nuclei were purified from cell lines: HcoEpiC, HeLa, HCT116, DLD1, HT29 and SW480 following published procedure $[43,44]$. Total nuclear proteins extracts were prepared in RIPA-Buffer. Equal amount of nuclear proteins were fractioned on SDS page gels, stained and analyzed on Odyssey and amounts were adjusted to equal amount of histone H4 for further analysis. Samples containing equal amount of histone $\mathrm{H} 4$ were fractioned on SDS page gel and the amounts of CENP-A, HJURP, ATRX, DAXX and histone H4 were determined by quantitative western blot analysis. Relative concentration of CENP-A in different cell lines was calculated as ratio CENP-A/H4 in a cell line divided by ratio of CENP-A/ H4 in normal colon cells. Relative concentrations of ATRX, DAXX, and HJURP were calculated similarly.

Table 7 CENP-A is enriched at the 8q24/Myc locus in tumor-derived SW480 cells and in human tumors

\begin{tabular}{lcccc}
\hline & Cell line/tumor & Probe & Cells with co-localization ${ }^{\text {a }}$ (\%) & Cells counted (N) \\
\hline Cell Line & HeLa & Myc & 5 & 20 \\
Cell Line & SW480 & Myc & 66 & 32 \\
Cell Line & Normal Colon & $8 \mathrm{q} 24$ & 1 & 100 \\
Cell Line & HeLa & $8 \mathrm{q} 24$ & 8 & 100 \\
Cell Line & SW480 & $8 \mathrm{q} 24$ & 38 & 100 \\
Tissue & Normal & $8 \mathrm{q} 24$ & 0 & 30 \\
Tissue & Tumor $\mathbf{1}$ & $8 \mathrm{q} 24$ & 32.9 & 82 \\
Tissue & Tumor2 & $8 \mathrm{q} 24$ & 36.5 & 85 \\
Tissue & Tumor $\mathbf{3}$ & $8 \mathrm{q} 24$ & 42.9 & 49 \\
Tissue & Tumor $\mathbf{4}$ & $8 \mathrm{q} 24$ & 78.4 & 88 \\
\hline
\end{tabular}

${ }^{a}$ Quantification of CENP-A and 8q24/Myc co-localization in cancer cells and tumors after co-immunofluorescence demonstrates that a statistically significant enrichment of CENP-A occurs on one of the translocated 8q24/Myc loci. White spots denoting co-localization were detected using Image J's automated co-localization algorithm. 


\section{Quantitative western blot analysis}

Quantitative infrared western blotting was performed using Odyssey Li-Cor CLx system (Lincoln, NE, USA). Briefly, infrared western blot (WB) signal was acquired with high dynamic range and analyzed using Image Studio software. Bands of interest were manually selected and their total intensity quantified with subtraction of median background signal from an area 3-pixels wide above and below the band in the same lane. The resulting total infrared signal values (arbitrary unit) were used for subsequent calculations as indicated.

\section{Chromatin immunoprecipitation}

CENP-A, and CENP-B chromatin immunoprecipitation (ChIP) for WB analysis was performed following published protocol [43,44]. Briefly, cells were harvested, washed with PBS once, PBS containing 0.1\% Tween 20 three times and nuclei were released with TM2 buffer (20 mM Tris- $\mathrm{HCl}, \mathrm{pH}$ 8.0; $2 \mathrm{mM} \mathrm{MgCl}_{2}$ ) containing $0.5 \%$ Nonidet P40 (Sigma) and $0.5 \mathrm{mM}$ PMSF. The nuclei were washed with TM2 buffer to remove detergent once. To release chromatin, nuclei were digested with $0.3 \mathrm{U} / \mathrm{ml}$ MNase (Sigma) for 8 mins and reaction was stopped with the addition of $10 \mathrm{mM}$ EGTA. Nuclei were extracted in low salt buffer (0.5X PBS containing $5 \mathrm{mM}$ EGTA and $0.5 \mathrm{mM}$ PMSF) over night at $4^{\circ} \mathrm{C}$. Chromatin IP was performed using Dynabeads-protein G (Life Technologies, Grand Island, NY, USA), Agarose protein A/G plus (Santa Cruz, Santa Cruz, CA, USA) or protein G sepharose 4 Fast flow (GE Healthcare, Laurel, MD, USA) and antibodies listed below.

\section{Antibodies used for chromatin immunoprecipitation, western blot, and immunofluorescence}

CENP-A: rabbit CENP-A (Santa Cruz; SC-22787, Santa Cruz, CA, USA); rabbit CENP-A (Millipore; 07-574, Billerica, MA, USA), custom CENP-A (CSEM laboratory); mouse CENP-A (Abcam, ab13939, Cambridge, MA, USA); goat CENP-A (Santa Cruz, sc-11277). HJURP: rabbit HJURP (Bethyl, A302-822A, Montgomery, TX, USA). $\mathrm{H}_{2}$ A.Z: rabbit $\mathrm{H}_{2}$ A.Z (Abcam, ab4174). CENP-C: goat CENP-C (Santa Cruz, sc11285). CENP-B: rabbit CENP-B (Santa Cruz, sc-22788), rabbit CENP-B (abcam, ac25743). ACA serum (Centromere Ab Positive Serum) BBI Solutions (Cat \#SG140-2, Lot \#3284-146-2, Cardiff, UK).

Chromatin IP for CHIP-Seq was performed similarly as above, except for the following modifications: MNase concentration was $0.6 \mathrm{U} / \mathrm{ml}$, digestion time was $10 \mathrm{~min}$ for cancer cells and $8 \mathrm{~min}$ for normal HcoEpiC cells, and nuclei were treated with 0.05 to $0.1 \%$ formaldehyde for gentle in situ crosslinking within intact nuclei for 30 min at RT, as indicated in ENCODE protocols, before extraction of chromatin in low salt buffer. IP-enriched chromatin was eluted with $100 \mathrm{mM} \mathrm{NaHCO}$ and $1 \%$
SDS at $65^{\circ} \mathrm{C}$ for $2 \mathrm{~h}$. To reverse cross-linking, $\mathrm{NaCl}$ was added to the final $200 \mathrm{mM}$ concentration and incubated at $67^{\circ} \mathrm{C}$ for additional $4 \mathrm{~h}$ followed by RNase A $(150 \mu \mathrm{g} / \mathrm{ml})$ treatment for $1 \mathrm{~h}$ and then proteins were digested with proteinase $\mathrm{K}(100 \mu \mathrm{g} / \mathrm{ml})$ for $3 \mathrm{~h}$. The DNA was purified by phenol extraction and ethanol precipitated. The DNA was repaired using PreCR Repair mix (New England Biolabs, Ipswich, MA, USA) following manufacturer's instructions. DNA was purified using Chroma Spin columns (Clontech, Mountain View, CA, USA).

\section{Nucleosome reconstitution in vitro}

Lyophilized recombinant histones (a gift from Jennifer Ottesen) were unfolded in $7 \mathrm{M}$ guanidinium $\mathrm{HCl}$, mixed in equimolar amounts (Either H3 or CENP-A and one each $\mathrm{H} 2 \mathrm{~A}, \mathrm{H} 2 \mathrm{~B}, \mathrm{H} 4$ ), and refolded into $2 \mathrm{M} \mathrm{NaCl}$ according to the protocol by Luger et al. [74]. Refolded nucleosomes were reconstituted onto a plasmid containing a 'Widom 601' positioning sequence (a gift from Carl $\mathrm{Wu}$ ) using sequential salt dialysis adapted for low volumes. Briefly, histone octamers were mixed with plasmid DNA at 0.9:1 ratio in $2 \mathrm{M} \mathrm{NaCl}, 10 \mathrm{mM}$ Tris-Cl $\mathrm{pH}=8.0,1 \mathrm{mM}$ EDTA $(0.18 \mathrm{mg} / \mathrm{ml}$ histones; $0.2 \mathrm{mg} / \mathrm{ml}$ DNA) and incubated on ice for $30 \mathrm{~min}$. Next, $40 \mathrm{ul}$ of histone/DNA mix was layered onto a dialysis disc (Millipore, $0.025 \mathrm{um}$, Billerica, MA, USA) covered with a dialysis membrane (Thermo Scientific, 7000 MWCO, Waltham, MA, USA) and floated on the surface of $50 \mathrm{ml}$ pre-chilled $1 \mathrm{M} \mathrm{NaCl}, 10 \mathrm{mM}$ Tris-Cl pH =8.0, $1 \mathrm{mM}$ EDTA buffer. Sequential dialysis steps against $1 \mathrm{M}, 0.8 \mathrm{M}, 0.6 \mathrm{M}$, and $0.15 \mathrm{M} \mathrm{NaCl}$ (each with $10 \mathrm{mM}$ Tris- $\mathrm{Cl} \mathrm{pH}=8.0,1 \mathrm{mM}$ EDTA) were carried out for 2 hours at $4^{\circ} \mathrm{C}(0.6 \mathrm{M}$ dialysis was done overnight). Reconstituted chromatin was diluted one hundredfold in $1 \mathrm{X}$ PBS, $2 \mathrm{mM} \mathrm{MgCl}_{2}$ buffer and imaged on AP-mica [75].

\section{Atomic force microscopy imaging and analysis}

AFM imaging of bulk and immunoprecipitated CENP-A chromatin was performed essentially as described previously $[43,44]$ with some adaptations (see manual analysis below). Extracted or IP-eluted chromatin was deposited on APS-mica (prepared as described by Dimitriadis et al., 2010 [43]) in the presence of divalent magnesium ions. The sample was incubated for 10 minutes, briefly rinsed with MilliQ water, and dried in a vacuum chamber. The sample was imaged using AFM 5500 (Agilent Technologies, now Keysight Technologies, Santa Clara, CA, USA) operating in AC mode (noncontact/tapping), equipped with either OTESPA or TESP silicone tip (Bruker Nano, Santa Barbara, CA, USA) with a nominal radius of 3 to 7 $\mathrm{nm}$. Images were captured at 4096x4096 resolution with an instrument operating at setpoint equivalent to $65 \%$ to $75 \%$ of free amplitude (typically 1.5 to $2.5 \mathrm{~V}$ ). 
Acquired images were processed using Gwyddion (gwyddion.net) software (flattening, line correction, and polynomial background subtraction) and analyzed either manually (see below), or, for bulk controls, using NIH Image J software (imagej.nih.gov/ij/) Particle Analysis function. Briefly, the images were limited by threshold (to remove tip convolution) and filtered to include only round or elliptical shapes. Max. height, total area, and volume information was collected. SigmaPlot software was used to statistically analyze the data and generate graphs. For ectopic and recombinant CENP-A and H3 nucleosomes, manual measurements were performed in Gwyddion software to ensure that strictly DNA-associated particles were included (diameter cutoff $<20 \mathrm{~nm}$ ).

\section{BioAnalyzer analysis of DNA fragments obtained from chromatin immunofluorescence}

DNA samples were prepared according to manufacturer's recommendations and ran on High Sensitivity DNA Chips (Agilent Cat \#5067-4626, Wilmington, DE, USA) on the Agilent 2100 BioAnalyzer system. Data with the control lower and upper limits were automatically called or manually aligned (see figure) with the Agilent 2100 Expert Software.

\section{DNase I digestion of chromatin from HeLa and SW480}

HeLa and SW480 cells were harvested with trypsin, washed twice with ice cold PBS containing 0.1\% Tween 20 , and resuspend in low sucrose buffer (15 mM Tris$\mathrm{HCl}, \mathrm{PH}$ 8.0, $15 \mathrm{mM} \mathrm{NaCl}, 60 \mathrm{mM} \mathrm{KCl}, 1 \mathrm{mM}$ EDTA, $0.5 \mathrm{mM}$ EGTA, $1 \mathrm{mM}$ spermidine, EDTA free protease inhibitors). Cells were mixed (1:1) with same buffer containing $0.04 \%$ NP-40 and nuclei were released at $4^{\circ} \mathrm{C}$. Nuclei were harvested by centrifugation, washed with low sucrose buffer and DNase I digestion was performed with 20 million nuclei as previously described [76,77]. DNA fragments of 100 to 500 bp from a chromatin digestion with $60 \mathrm{U} / \mathrm{ml}$ DNase I (Sigma, St. Louis, MO, USA) were purified using sucrose gradient [77] and DNA was precipitated in 0.1 volume of sodium acetate and 0.7 volume of isopropanol.

Bioinformatic analysis of chromatin immunoprecipitationseq, DNase-seq, and TOMTOM DNA motif enrichment

Purified DNA from ChIP or DNase I digested chromatin were used to prepare libraries for Illumina highthroughput sequencing as described in manufacturer's protocol (Illumina Sequencing, San Diego, CA, USA). Libraries were sequenced to generate $35 \mathrm{bp}$ single end reads using Illumina GAII sequencer at the Advanced Technology Center, NCI (Frederick, MD). Sequence reads were mapped to the reference genome hg19 by the CASAVA 1.8.2 pipeline.

\section{Hotspot detection for DNase-seq}

We identified regions of local enrichment of sequence tags using a hotspot detection algorithm essentially as previously described $[55,77]$ with a false discovery rate (FDR) of $0.1 \%$.

\section{Hotspot detection and input adjustment for chromatin immunoprecipitation-seq}

The hotspot detection algorithm was similarly applied to ChIP-seq data with the following modification. The sequencing data from matching input samples are used for the processing of ChIP data, as a measure of background signal that might be significant. After normalizing the input data to match the number of tags in the ChIP data, the number of input tags is subtracted from the number of ChIP tags in the target window before calculating its z-score.

\section{DNA Motif discovery analysis}

A motif discovery analysis on selected DNA sequences was performed using MEME [78] on a parallel cluster at the NIH Biowulf supercomputing facility (meme.nbcr.net/). DNA sequences for MEME input were from the top 2000 (by tag density) hotspots. To limit the computational load, only the 200-bp regions with the highest tag density were used instead of the entire width of hotspots in cases where the hotspots spanned greater than $200 \mathrm{bp}$. The width of motif for searching was set to 6 and 20 for minimum and maximum, respectively. To identify binding motifs for known transcription factors, we queried individual position-specific matrices against the Transfac database using the Tomtom software (http://meme.nbcr. net/meme/cgi-bin/tomtom.cgi). We retrieved statistically significant matches that share the majority of specific nucleotides in the sequence motifs.

\section{Quantitative PCR analysis}

Quantitative (real time) PCR was performed using the IQ-Sybr Green Supermix kit from BioRad (\#170-8880, Hercules, CA, USA) in $25 \mu \mathrm{l}$ reaction according to the manufacturer's protocol and samples were amplified using I-cycler fitted with MyIQ Single color real time PCR detection system (BioRad, Hercules, CA, USA). In all experiments no template- and Mock IP (normal IgG IP; negative control) controls, and input chromatin DNA and IP samples (CENP-A \& CENP-C) were included from same experiment. The qtPCR reactions were setup in triplicate thus giving three threshold cycle numbers $(\mathrm{Ct})$ for each sample. Experiment was repeated three separate times. Enrichments and fold changes were calculated as follows:

$$
\begin{aligned}
& \text { Ct.i }=\text { average } \mathrm{Ct} \text { of input } \\
& \text { Ct.m = average } \mathrm{Ct} \text { of mock IP } \\
& \text { Ct.IP = average Ct of IP samples (CENP-A and CENP-C) } \\
& \text { STDV.i = standard deviation of input }
\end{aligned}
$$


STDV.m $=$ standard deviation of mock

STDV.IP = standard deviation of IP

Step 1. Calculate $\Delta \mathrm{Ct}$ and STDV $\Delta \mathrm{Ct}$ for CENP-A, CENP-C and Mock IP using the following formulas:

$$
\begin{aligned}
& \Delta \mathrm{Ct}=\text { Ct.i-Ct.IP (CENP-A, CENP-C or Mock) } \\
& S T D V \Delta C t=S Q R T\left[(S T D V i)^{2}+(S T D V I P)^{2}\right] / S Q R T(2)
\end{aligned}
$$

Step 2. Transform $\Delta \mathrm{Ct}$ and STDV $\Delta \mathrm{Ct}$ (with respect to input) to input to linear scale fold change (FC) and fold change error $(\mathrm{E})$ as follows:

$$
\mathrm{FCIP}=2^{\wedge} \Delta \mathrm{Ct}
$$

$$
\mathrm{E}=\log (2) * \mathrm{FC} * \mathrm{STDV} \Delta \mathrm{Ct}
$$

Step 3 Fold Enrichment $=$ FC of IP/ FC of Mock IP \pm E

\section{Identification and labeling of fluorescent in situ hybridization probe for $8 \mathrm{q} 24 / \mathrm{Myc}$}

Five overlapping bacterial artificial chromosomes (BAC) containing human chromosome 8q24 region (chr 8: $125,771,341-127,401,859)$ and a larger region spanning $8 \mathrm{q} 24 /$ Myc (location of both probes are depicted on Figure $8 \mathrm{~B}$ ) were selected and obtained from commercial source (Invitrogen, Grand Island, NY, USA). DNA was isolated from each BAC and labeled with biotin-dUTP and hybridized to normal blood lymphocytes metaphasespread slides. Each BAC was evaluated for intensity and specificity of hybridization at target region. The BAC named RP11-150 N13 was selected to be used as a probe for 8q24 (chr 8:126,377,028 to $126,556,325$ ), and a previously published $M y c$ probe was used to confirm the results [79]. For probes, $2 \mu \mathrm{g}$ BAC DNA was labeled with biotindUTP by nick translation in the presence of $4 \mathrm{nmol} / \mathrm{L}$ labeled nucleotide. Approximately 100 to $200 \mathrm{ng}$ of labeled $\mathrm{BAC}$ probe was ethanol precipitated in the presence of 20 $\mu \mathrm{g}$ each salmon sperm DNA and human Cot1 DNA. The dry pellet was dissolved in 5 to $6 \mu$ of hybridization buffer. The hybridization buffer contained $50 \%$ deionized formamide, 20\% dextran sulfate and $4 \mathrm{X}$ SSC. The probe was denatured for $5 \mathrm{~min}$ at $80^{\circ} \mathrm{C}$ and then pre-annealed for $1 \mathrm{~h}$ at $37^{\circ} \mathrm{C}$ before adding to the slides for hybridization.

\section{Co-immunofluorescence and fluorescent in situ hybridization experiments}

The IF on metaphase chromosomes, interphase cells from cell lines and tumor-normal patient sample cells, was performed on unfixed cells following published protocol with some modifications [80,81]. Enrichment of mitotic cells was achieved by double thymidine block to arrest cells in G1 phase of cells cycle. Actively growing culture was treated $5 \mathrm{mM}$ thymidine for 18 to $20 \mathrm{~h}$. The cells were released from first block and grown in fresh medium for $10 \mathrm{~h}$ followed by second block with $5 \mathrm{mM}$ thymidine for $12 \mathrm{~h}$. Cells were released from second block and cultured further in fresh medium for $9 \mathrm{~h}$. These cells were either harvested to make slides or treated with $100 \mu \mathrm{g} / \mathrm{ml}$ colcemid (Roche, Indianapolis, IN, USA) for $1 \mathrm{~h}$ to make metaphase chromosomes and then harvested to make slides. The cells were harvested with trypsin and washed with PBS, resuspended in $75 \mathrm{mM} \mathrm{KCl}$, and incubated at $37^{\circ} \mathrm{C}$ for $13 \mathrm{~min}$ and then placed on ice. Cells were cytospun onto glass slides for $5 \mathrm{~min}$ at $600 \mathrm{rpm}$. After air drying, the slides were incubated in freshly prepared KCM buffer $(120 \mathrm{mM} \mathrm{KCl}, 20 \mathrm{mM} \mathrm{NaCl}, 10 \mathrm{mM}$ Tris-HCl, pH 8.0, $0.5 \mathrm{mM}$ EDTA) containing $0.1 \%$ Triton $\mathrm{X}-100$ and protease inhibitors $(1 \mu \mathrm{g} / \mathrm{ml}$ aprotinin, pepstatin A, Leupeptin and antipain each) for $15 \mathrm{~min}$ at room temperature (RT) followed by blocking (KCM buffer containing 3\% BSA, protease inhibitors and 1:100 dilution normal $\operatorname{IgG}$ ) for 30 min and primary antibody (KCM buffer containing $1 \%$ BSA, protease inhibitors and 1:100 dilution normal IgG) for $1 \mathrm{~h}$. The slides were washed with KCM three times 5 min each at RT followed by secondary antibody staining for $1 \mathrm{~h}$ at RT. The slides were washed with KCM buffer four times 5 min each at RT, fixed with $10 \%$ buffered formalin for $10 \mathrm{~min}$ at $\mathrm{RT}$, washed with $\mathrm{H}_{2} \mathrm{O}$ three times 5 min each at RT, incubated in carnoy's fixture for $30 \mathrm{~min}$ at RT followed by dehydration in ethanol series $(70,95$ and $100 \%$ ethanol) 5 min each and air dried.

For FISH, slides were equilibrated in 2X SSC for 5 min and digested with pepsin $(10 \mu \mathrm{g} / \mathrm{ml})$ for $3 \mathrm{~min}$ at $37^{\circ} \mathrm{C}$. Pepsin digestion time varied for different samples based on amount of cytoplasm left after spinning cells on slides or age of slides. The slides were washed three times in 2X SSC and dehydrated in ethanol series. The DNA on slides was denatured in $70 \%$ formamide and $2 \mathrm{X}$ $\mathrm{SSC}$ at $80^{\circ} \mathrm{C}$ for $5 \mathrm{~min}$. The slides were incubated in ice cold $70 \%$ and $95 \%$ ethanol for $3 \mathrm{~min}$ each followed by $100 \%$ ethanol for $5 \mathrm{~min}$ at RT. Then denatured slides were hybridized with pre-annealed for 20 to $24 \mathrm{~h}$ at $37^{\circ} \mathrm{C}$. At the end of hybridization, the slides were washed in $50 \%$ formamide and 2X SSC three times for 5 min each at $45^{\circ} \mathrm{C}, 0.2 \mathrm{X} \mathrm{SSC}$ four times for $5 \mathrm{~min}$ each at $65^{\circ} \mathrm{C}$ and 2X SSC at room temperature once for $5 \mathrm{~min}$. After washing, slides were incubated with blocking buffer $(4 \times$ $\mathrm{SSC} / 0.1 \%$ Tween-20,3\% bovine albumin) containing normal sheep or goat IgG (1:100 dilution) for $1 \mathrm{~h}$ at $37^{\circ} \mathrm{C}$. The slides were then incubated with 1:1000 dilution streptavidin alexa 488 (Invitrogen, Grand Island, NY, USA) in developing buffer (4X SSC/0.1\% Tween 20, 1\% BSA) containing normal IgG for $1 \mathrm{~h}$. The slides were washed in $4 \mathrm{X}$ SSC $/ 0.1 \%$ tween 20 solution four times at $45^{\circ} \mathrm{C}$ followed by two washes in 2X SSC at room temperature. Slides were air dried and mounted with aqueous mounting media containing DAPI (Vector Labs, Burlingame, CA, 
USA). The slides were observed with a DeltaVision RT system (Applied Precision, GE Healthcare, Issaquah, WA, USA) controlling an interline charge-coupled device camera (Coolsnap; Roper) mounted on inverted microscope (IX-70; Olympus America, Center Valley, PA, USA). Images were captured using the $100 \mathrm{X}$ objective at $0.06 \mu \mathrm{m}$ z-sections, de-convolved, and 2D-projected using softWoRx (api.gehealthcare.com/api/softworx-suite. asp). One hundred interphase cells were analyzed for CENP-A and 8q24 for all cell lines. For tumors, the number of cells analyzed ranged from 70 to 85 except for one tumor in which fifty cells were analyzed due to insufficient material.

\section{Tumor and matched normal tissue}

Tumor/normal tissues were obtained from the CHTN network. The pathology report indicated Tumor 1, Tumor 2 , and Tumor 3 were moderately differentiated stage three tumor with no metastasis, high grade poorly differentiated stage three tumor with metastasis to one lymph node, and low grade well differentiated stage three tumor with no metastasis, respectively. Tumor cells were minced in buffer containing $250 \mathrm{mM}$ sucrose, $15 \mathrm{mM}$ Tris- $\mathrm{HCl} \mathrm{PH} 7.5$, $15 \mathrm{mM} \mathrm{NaCl}, 60 \mathrm{mM} \mathrm{KCl}, 1 \mathrm{mM}$ EDTA, 0.5 mM EGTA, $0.15 \mathrm{mM}$ spermine, $0.5 \mathrm{mM}$ Spermidine and protease inhibitors (adapted from Dalal et al., 2005 [82]). Cells were collected by centrifugation at $600 \mathrm{~g}(1500 \mathrm{rpm})$ for $10 \mathrm{~min}$ at $4^{\circ} \mathrm{C}$. The cell pellet was washed twice with same buffer. The cell pellet was resuspended in buffer containing $2 \mathrm{M}$ sucrose instead of $250 \mathrm{mM}$ and spun at $16,000 \times \mathrm{g}$ for 30 $\min$ at $4^{\circ} \mathrm{C}$. The cells were washed with buffer containing no sucrose and cells were cytospun onto glass slides for $5 \mathrm{~min}$ at $600 \mathrm{rpm}$. The slides were air dried and processed for IF and FISH as above.

\section{Additional file}

\section{Additional file 1: Genome wide chromatin immunoprecipitation} (ChIP)-Seq and DNase I hypersensitivity (DHS)-Seq identifies CENP-A and DHS sites in colorectal cancer cells. (A list of all hotspots identified in this study (please find attached as an xls data/spreadsheet).

\section{Abbreviations}

CENP-A (-B/C/N): centromere protein A (B/C/N); DHS: DNase I hypersensitive site; HJURP: Holliday junction recognition protein; MNase: micrococcal nuclease; ChIP: chromatin immunoprecipitation; WB: western blotting; ACA: anti-centromere antibody.

\section{Competing interests}

The authors declare that they have no competing interests.

\section{Authors' contributions}

YD, RKG, MW and SF designed the study; RKG and MW performed biochemical analyses in cancer cell lines; MW performed all AFM analyses; RKG performed IF/FISH experiments in cancer cells lines and tumors; SF performed DHS experiments; MB performed ACA experiments; SB and MS performed bioinformatics analyses; JC and TR provided chromosomal translocation data. RKG, MW, SB, and SF contributed unique reagents and tools to this study. RKG, MW, SB, and YD analyzed the data, and YD and MW wrote the paper. All authors read and approved the final manuscript.

\section{Acknowledgements}

We thank the NCI-ATP SAIC High Throughput Illumina Sequencing Facility for deep sequencing and subsidies; Dr. Carl Wu for the gift of 601 plasmid; Dr. Jennifer Otteson for the gift of recombinant histones; Dr. Sam John for expert advice on DHS assays; Drs. Andre Nussenzweig, Tom Misteli, Minh Bui, and Delphine Quenet for critical comments on the manuscript; Tatiana Karpova in the LRBGE Imaging Facility; and the Mid-Atlantic Cooperative Human Tissue Network for tumor samples.

\section{Funding}

The Intramural Research Program of the National Cancer Institute supported all authors in this study. SF volunteered as a guest researcher for the bulk of this study and was subsequently supported by the NCl post-baccalaureate program.

\section{Author details}

${ }^{1}$ Chromatin Structure and Epigenetics Mechanisms Unit, Center for Cancer Research, National Cancer Institute National Institutes of Health, 41 Center Drive, Bethesda, MD 20892, USA. 'Laboratory of Receptor Biology and Gene Expression, Center for Cancer Research, National Cancer Institute National Institutes of Health, 41 Center Drive, Bethesda, MD 20892, USA. ${ }^{3}$ Genetics Branch, Center for Cancer Research, National Cancer Institute National Institutes of Health, 50 South Drive, Bethesda, MD 20892, USA.

Received: 26 November 2014 Accepted: 1 December 2014 Published: 13 January 2015

\section{References}

1. Chan TA, Glockner S, Yi JM, Chen W, Van Neste L, Cope L, et al. Convergence of mutation and epigenetic alterations identifies common genes in cancer that predict for poor prognosis. PLoS Med. 2008;5:e114.

2. Thompson SL, Compton DA. Chromosomes and cancer cells. Chromosome Res. 2011;19:433-44.

3. Ganem NJ, Pellman D. Linking abnormal mitosis to the acquisition of DNA damage. J Cell Biol. 2012;199:871-81.

4. Holland AJ, Cleveland DW. The deubiquitinase USP44 is a tumor suppressor that protects against chromosome missegregation. J Clin Invest. 2012;122:4325-8.

5. Gordon DJ, Resio B, Pellman D. Causes and consequences of aneuploidy in cancer. Nat Rev Genet. 2012;13:189-203

6. Forment JV, Kaidi A, Jackson SP. Chromothripsis and cancer: causes and consequences of chromosome shattering. Nat Rev Cancer. 2012;12:663-70.

7. Stimpson KM, Song IY, Jauch A, Holtgreve-Grez H, Hayden KE, Bridger JM, et al. Telomere disruption results in non-random formation of de novo dicentric chromosomes involving acrocentric human chromosomes. PLoS Genet. 2010;6: doi:10.1371/journal.pgen.1001061.

8. Downs JA, Nussenzweig MC, Nussenzweig A. Chromatin dynamics and the preservation of genetic information. Nature. 2007:447:951-8.

9. Barlow JH, Faryabi RB, Callen E, Wong N, Malhowski A, Chen HT, et al. Identification of early replicating fragile sites that contribute to genome instability. Cell. 2013;152:620-32.

10. Tomonaga T, Matsushita K, Yamaguchi S, Oohashi T, Shimada H, Ochiai T, et al. Overexpression and mistargeting of centromere protein- $\mathrm{A}$ in human primary colorectal cancer. Cancer Res. 2003;63:3511-6.

11. Tomonaga T, Matsushita K, Ishibashi M, Nezu M, Shimada H, Ochiai T, et al. Centromere protein $\mathrm{H}$ is up-regulated in primary human colorectal cancer and its overexpression induces aneuploidy. Cancer Res. 2005;65:4683-9.

12. Sullivan $L L$, Boivin $C D$, Mravinac $B$, Song IY, Sullivan BA. Genomic size of CENP-A domain is proportional to total alpha satellite array size at human centromeres and expands in cancer cells. Chromosome Res. 2011;19:457-70.

13. Amato A, Schillaci T, Lentini L, Di Leonardo A. CENPA overexpression promotes genome instability in pRb-depleted human cells. Mol Cancer. 2009;8:119.

14. Verdaasdonk JS, Bloom K. Centromeres: unique chromatin structures that drive chromosome segregation. Nat Rev Mol Cell Biol. 2011;12:320-32.

15. Guse A, Carroll CW, Moree B, Fuller CJ, Straight AF. In vitro centromere and kinetochore assembly on defined chromatin templates. Nature. 2011;477:354-8 
16. Santaguida S, Musacchio A. The life and miracles of kinetochores. EMBO J. 2009;28:2511-31.

17. Heun P, Erhardt S, Blower MD, Weiss S, Skora AD, Karpen GH. Mislocalization of the Drosophila centromere-specific histone CID promotes formation of functional ectopic kinetochores. Dev Cell. 2006;10:303-15.

18. McGovern SL, Qi Y, Pusztai L, Symmans WF, Buchholz TA, et al. Centromere protein-A, an essential centromere protein, is a prognostic marker for relapse in estrogen receptor-positive breast cancer. Breast Cancer Res. 2012;14:R72.

19. Olszak AM, van Essen D, Pereira AJ, Diehl S, Manke T, Maiato H, et al. Heterochromatin boundaries are hotspots for de novo kinetochore formation. Nat Cell Biol. 2011;13:799-808.

20. Van Hooser AA, Ouspenski II, Gregson HC, Starr DA, Yen TJ, Goldberg ML, et al. Specification of kinetochore-forming chromatin by the histone $\mathrm{H3}$ variant CENP-A. J Cell Sci. 2001;114:3529-42.

21. Lam AL, Boivin CD, Bonney CF, Rudd MK, Sullivan BA. Human centromeric chromatin is a dynamic chromosomal domain that can spread over noncentromeric DNA. Proc Natl Acad Sci U S A. 2006;103:4186-91.

22. Moreno-Moreno O, Torras-Llort M, Azorin F. Proteolysis restricts localization of $\mathrm{CID}$, the centromere-specific histone $\mathrm{H} 3$ variant of Drosophila, to centromeres. Nucleic Acids Res. 2006;34:6247-55.

23. Hewawasam G, Shivaraju M, Mattingly M, Venkatesh S, Martin-Brown S, Florens L, et al. Psh1 is an E3 ubiquitin ligase that targets the centromeric histone variant Cse4. Mol Cell. 2010;40:444-54.

24. Lacoste N, Woolfe A, Tachiwana H, Garea AV, Barth T, Cantaloube S, et al. Mislocalization of the centromeric histone variant CenH3/CENP-A in human cells depends on the chaperone DAXX. Mol Cell. 2014;53:631-44.

25. Qiu JJ, Guo JJ, Lv TJ, Jin HY, Ding JX, Feng WW, et al. Prognostic value of centromere protein-A expression in patients with epithelial ovarian cancer. Tumour Biol. 2013;34:2971-5.

26. Wu Q, Qian YM, Zhao XL, Wang SM, Feng XJ, Chen XF, et al. Expression and prognostic significance of centromere protein $\mathrm{A}$ in human lung adenocarcinoma. Lung Cancer. 2012;77:407-14.

27. Hu Z, Huang G, Sadanandam A, Gu S, Lenburg ME, Pai M, et al. The expression level of HJURP has an independent prognostic impact and predicts the sensitivity to radiotherapy in breast cancer. Breast Cancer Res. 2010;12:R18.

28. Earnshaw W, Bordwell B, Marino C, Rothfield N. Three human chromosomal autoantigens are recognized by sera from patients with anti-centromere antibodies. J Clin Invest. 1986;77:426-30

29. Palmer DK, O'Day K, Wener MH, Andrews BS, Margolis RL. A 17-KD centromere protein (CENP-A) copurifies with nucleosome core particles and with histones. J Cell Biol. 1987;104:805-15.

30. Bernad R, Sanchez P, Rivera T, Rodriguez-Corsino M, Boyarchuk E, Vassias I, et al. Xenopus HJURP and condensin II are required for CENP-A assembly. J Cell Biol. 2011;192:569-82.

31. Foltz DR, Jansen LE, Bailey AO, Yates 3rd JR, Bassett EA, Wood S, et al. Centromere-specific assembly of CENP-a nucleosomes is mediated by HJURP. Cell. 2009;137:472-84.

32. Dunleavy EM, Roche D, Tagami H, Lacoste N, Ray-Gallet D, Nakamura Y, et al. HJURP is a cell-cycle-dependent maintenance and deposition factor of CENP-A at centromeres. Cell. 2009;137:485-97.

33. Greaves IK, Rangasamy D, Ridgway P, Tremethick DJ. H2A.Z contributes to the unique 3D structure of the centromere. Proc Natl Acad Sci U S A. 2007;104:525-30

34. Jin C, Felsenfeld G. Nucleosome stability mediated by histone variants H3.3 and H2A.Z. Genes Dev. 2007;21:1519-29.

35. Masumoto $H$, Masukata H, Muro Y, Nozaki N, Okazaki T. A human centromere antigen (CENP-B) interacts with a short specific sequence in alphoid DNA, a human centromeric satellite. J Cell Biol. 1989;109:1963-73.

36. Hasson D, Panchenko T, Salimian KJ, Salman MU, Sekulic N, Alonso A, et al. The octamer is the major form of CENP-A nucleosomes at human centromeres. Nat Struct Mol Biol. 2013;20:687-95

37. Shelby RD, Vafa O, Sullivan KF. Assembly of CENP-A into centromeric chromatin requires a cooperative array of nucleosomal DNA contact sites. J Cell Biol. 1997;136:501-13.

38. Bui M, Walkiewicz MP, Dimitriadis EK, Dalal Y. The CENP-A nucleosome: a battle between Dr Jekyll and Mr Hyde. Nucleus. 2013:4:37-42.

39. Tachiwana H, Kagawa W, Shiga T, Osakabe A, Miya Y, Saito K, et al. Crystal structure of the human centromeric nucleosome containing CENP-A. Nature. 2011;476:232-5.

40. Walkiewicz MP, Dimitriadis EK, Dalal Y. CENP-A octamers do not confer a reduction in nucleosome height by AFM. Nat Struct Mol Biol. 2014;21:2-3.
41. Yoda K, Ando S, Morishita S, Houmura K, Hashimoto K, Takeyasu K, et al. Human centromere protein A (CENP-A) can replace histone $\mathrm{H} 3$ in nucleosome reconstitution in vitro. Proc Natl Acad Sci U S A. 2000;97:7266-71.

42. Dalal $Y$, Wang $H$, Lindsay $S$, Henikoff S. Tetrameric structure of centromeric nucleosomes in interphase Drosophila cells. PLoS Biol. 2007;5:e218.

43. Dimitriadis EK, Weber C, Gill RK, Diekmann S, Dalal Y. Tetrameric organization of vertebrate centromeric nucleosomes. Proc Natl Acad Sci U S A. 2010;107:20317-22

44. Bui M, Dimitriadis EK, Hoischen C, An E, Quenet D, Giebe S, et al. Cell-cycledependent structural transitions in the human CENP-A nucleosome in vivo. Cell. 2012;150:317-26.

45. Luger K, Mader AW, Richmond RK, Sargent DF, Richmond TJ. Crystal structure of the nucleosome core particle at $2.8 \mathrm{~A}$ resolution. Nature. 1997;389:251-60

46. Tachiwana H, Kagawa W, Kurumizaka H. Comparison between the CENP-A and histone H3 structures in nucleosomes. Nucleus. 2012;3:6-11.

47. Henikoff S, Ramachandran S, Krassovsky K, Bryson TD, Codomo CA, Brogaard $\mathrm{K}$, et al. The budding yeast Centromere DNA Element II wraps a stable Cse4 hemisome in either orientation in vivo. Elife. 2014;3:e01861.

48. Krassovsky K, Henikoff JG, Henikoff S. Tripartite organization of centromeric chromatin in budding yeast. Proc Natl Acad Sci U S A. 2012;109:243-8.

49. Cole HA, Howard BH, Clark DJ. The centromeric nucleosome of budding yeast is perfectly positioned and covers the entire centromere. Proc Nat Acad Sci U S A. 2011;108:12687-92.

50. Blower MD, Sullivan BA, Karpen GH. Conserved organization of centromeric chromatin in flies and humans. Dev Cell. 2002;2:319-30.

51. Shuaib M, Ouararhni K, Dimitrov S, Hamiche A. HJURP binds CENP-A via a highly conserved $\mathrm{N}$-terminal domain and mediates its deposition at centromeres. Proc Natl Acad Sci U S A. 2010;107:1349-54.

52. Ranjitkar P, Press MO, Yi X, Baker R, MacCoss MJ, Biggins S. An E3 ubiquitin ligase prevents ectopic localization of the centromeric histone $\mathrm{H} 3$ variant via the centromere targeting domain. Mol Cell. 2010;40:455-64.

53. Groudine $\mathrm{M}$, Weintraub H. Propagation of globin DNAase I-hypersensitive sites in absence of factors required for induction: a possible mechanism for determination. Cell. 1982;30:131-9.

54. Wu C, Bingham PM, Livak KJ, Holmgren R, Elgin SC. The chromatin structure of specific genes: I. Evidence for higher order domains of defined DNA sequence. Cell. 1979:16:797-806.

55. John S, Sabo PJ, Thurman RE, Sung MH, Biddie SC, Johnson TA, et al. Chromatin accessibility pre-determines glucocorticoid receptor binding patterns. Nat Genet. 2011;43:264-8.

56. John S, Sabo PJ, Canfield TK, Lee K, Vong S, Weaver M, et al. Genome-Scale Mapping of DNase I Hypersensitivity. Curr Protoc Mol Biol. 2013;Chapter 27:Unit 21.27.

57. Nie Z, Hu G, Wei G, Cui K, Yamane A, Resch W, et al. c-Myc is a universal amplifier of expressed genes in lymphocytes and embryonic stem cells. Cell. 2012:151:68-79.

58. Rudd MK, Friedman C, Parghi SS, Linardopoulou EV, Hsu L, Trask BJ. Elevated rates of sister chromatid exchange at chromosome ends. PLoS Genet. 2007;3:e32.

59. Beroukhim R, Mermel CH, Porter D, Wei G, Raychaudhuri S, Donovan J, et al. The landscape of somatic copy-number alteration across human cancers. Nature. 2010;463:899-905.

60. Boerma EG, Siebert R, Kluin PM, Baudis M. Translocations involving 8q24 in Burkitt lymphoma and other malignant lymphomas: a historical review of cytogenetics in the light of todays knowledge. Leukemia. 2009:23:225-34

61. Popescu NC, Zimonjic DB. Chromosome-mediated alterations of the MYC gene in human cancer. J Cell Mol Med. 2002;6:151-9.

62. Feo $\mathrm{S}$, Di Liegro $\mathrm{C}$, Jones $\mathrm{T}$, Read M, Fried $\mathrm{M}$. The DNA region around the c-myc gene and its amplification in human tumour cell lines. Oncogene. 1994;9:955-61.

63. Huppi K, Pitt JJ, Wahlberg BM, Caplen NJ. The 8q24 gene desert: an oasis of non-coding transcriptional activity. Front Genet. 2012;3:69.

64. Camps J, Nguyen QT, Padilla-Nash HM, Knutsen T, McNeil NE, Wangsa D, et al. Integrative genomics reveals mechanisms of copy number alterations responsible for transcriptional deregulation in colorectal cancer. Genes Chromosomes Cancer. 2009:48:1002-17.

65. Screpanti E, De Antoni A, Alushin GM, Petrovic A, Melis T, Nogales E, et al. Direct binding of cenp- $C$ to the mis 12 complex joins the inner and outer kinetochore. Curr Biol. 2011;21:391-8. 
66. Furuyama T, Dalal Y, Henikoff S. Chaperone-mediated assembly of centromeric chromatin in vitro. Proc Natl Acad Sci U S A. 2006;103:6172-7.

67. Steiner FA, Henikoff S. Holocentromeres are dispersed point centromeres localized at transcription factor hotspots. Elife. 2014;3:e02025.

68. Shelby RD, Monier K, Sullivan KF. Chromatin assembly at kinetochores is uncoupled from DNA replication. J Cell Biol. 2000;151:1113-8.

69. Jansen $L E$, Black BE, Foltz DR, Cleveland DW. Propagation of centromeric chromatin requires exit from mitosis. J Cell Biol. 2007;176:795-805.

70. Strahl $B D$, Allis CD. The language of covalent histone modifications. Nature. 2000:403:41-5.

71. Ambartsumyan G, Gill RK, Perez SD, Conway D, Vincent J, Dalal Y, et al. Centromere protein A dynamics in human pluripotent stem cell self-renewal, differentiation and DNA damage. Hum Mol Genet. 2010;19:3970-82.

72. Zeitlin SG, Baker NM, Chapados BR, Soutoglou E, Wang JY, Berns MW, et al. Double-strand DNA breaks recruit the centromeric histone CENP-A. Proc Natl Acad Sci U S A. 2009;106:15762-7.

73. Arimura Y, Shirayama K, Horikoshi N, Fujita R, Taguchi H, Kagawa W, et al. Crystal structure and stable property of the cancer-associated heterotypic nucleosome containing CENP-A and H3.3. Sci Rep. 2014;4:7115.

74. Luger K, Rechsteiner TJ, Richmond TJ. Expression and purification of recombinant histones and nucleosome reconstitution. Methods Mol Biol. 1999;119:1-16.

75. Lyubchenko YL, Gall AA, Shlyakhtenko LS. Atomic force microscopy of DNA and protein-DNA complexes using functionalized mica substrates. Methods Mol Biol. 2001;148:569-78.

76. Crawford GE, Davis S, Scacheri PC, Renaud G, Halawi MJ, Erdos MR, et al. DNase-chip: a high-resolution method to identify DNase I hypersensitive sites using tiled microarrays. Nat Methods. 2006;3:503-9.

77. John S, Sabo PJ, Johnson TA, Sung MH, Biddie SC, Lightman SL, et al. Interaction of the glucocorticoid receptor with the chromatin landscape. Mol Cell. 2008;29:611-24.

78. Bailey TL, Gribskov M. Methods and statistics for combining motif match scores. J Comput Biol. 1998;5:211-21.

79. Heselmeyer-Haddad K, Berroa Garcia LY, Bradley A, Ortiz-Melendez C, Lee WJ, Christensen R, et al. Single-cell genetic analysis of ductal carcinoma in situ and invasive breast cancer reveals enormous tumor heterogeneity yet conserved genomic imbalances and gain of MYC during progression. Am J Pathol. 2012;181:1807-22

80. Gill RK, Vazquez MF, Kramer A, Hames M, Zhang L, Heselmeyer-Haddad K, et al. The use of genetic markers to identify lung cancer in fine needle aspiration samples. Clin Cancer Res. 2008;14:7481-7.

81. Van Hooser A, Brinkley WR. Methods for in situ localization of proteins and DNA in the centromere-kinetochore complex. Methods Cell Biol. 1999;61:57-80

82. Dalal Y, Fleury TJ, Cioffi A, Stein A. Long-range oscillation in a periodic DNA sequence motif may influence nucleosome array formation. Nucleic Acids Res. 2005:33:934-45.

doi:10.1186/1756-8935-8-2

Cite this article as: Athwal et al: CENP-A nucleosomes localize to transcription factor hotspots and subtelomeric sites in human cancer cells. Epigenetics \& Chromatin 2015 8:2.

\section{Submit your next manuscript to BioMed Central and take full advantage of:}

- Convenient online submission

- Thorough peer review

- No space constraints or color figure charges

- Immediate publication on acceptance

- Inclusion in PubMed, CAS, Scopus and Google Scholar

- Research which is freely available for redistribution 